\title{
A multiplex centrality metric for complex social networks: sex, social status, and family structure predict multiplex centrality in rhesus macaques
}

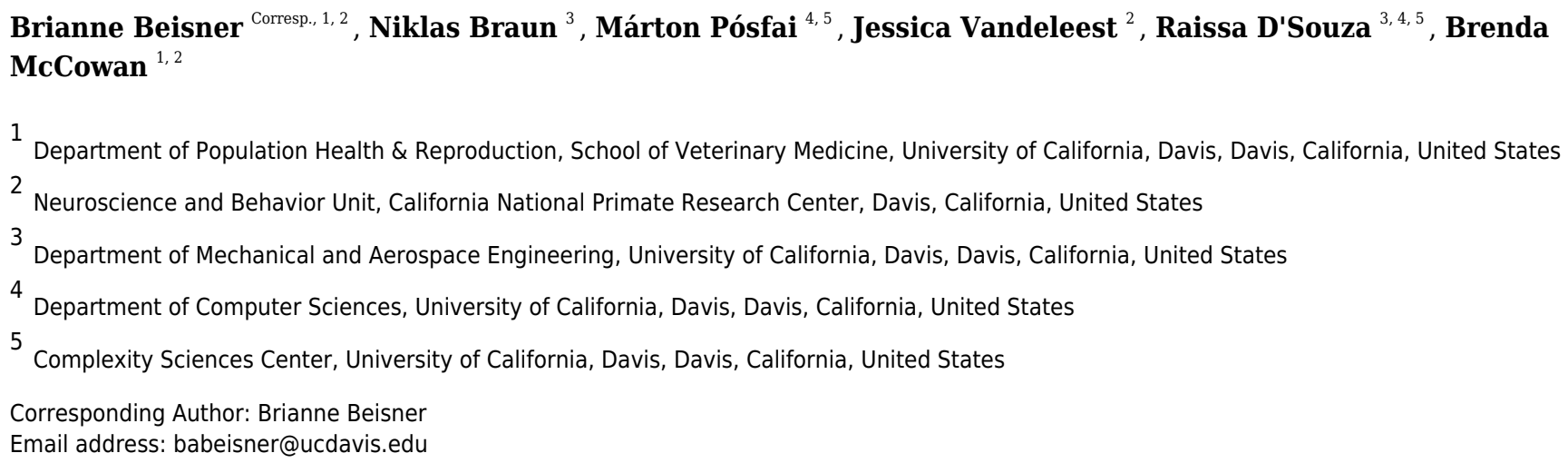

Members of a society interact using a variety of social behaviors, giving rise to a multifaceted and complex social life. For the study of animal behavior, quantifying this complexity is critical for understanding the impact of social life on animals' health and fitness. Multilayer network approaches, where each interaction type represents a different layer of the social network, have the potential to better capture this complexity than single layer approaches. Calculating individuals' centrality within a multilayer social network can reveal keystone individuals and more fully characterize social roles. However, existing measures of multilayer centrality do not account for differences in the dynamics and functionality across interaction layers. Here we validate a new method for quantifying multiplex centrality called consensus ranking by applying this method to multiple social groups of a well-studied nonhuman primate, the rhesus macaque. Consensus ranking can suitably handle the complexities of animal social life, such as networks with different properties (sparse vs. dense) and biological meanings (competitive vs. affiliative interactions). We examined whether individuals' attributes or socio-demographic factors (sex, age, dominance rank and certainty, matriline size, rearing history) were associated with multiplex centrality. Social networks were constructed for five interaction layers (i.e., aggression, status signaling, conflict policing, grooming and huddling) for seven social groups. Consensus ranks were calculated across these five layers and analyzed with respect to individual attributes and socio-demographic factors. Generalized linear mixed models showed that consensus ranking detected known social patterns in rhesus macaques, showing that multiplex centrality was greater in high-ranking males with high certainty of rank and females from the largest families. In addition, consensus ranks also 
showed that females from very small families and mother-reared (compared to nurseryreared) individuals were more central, showing that consideration of multiple social domains revealed individuals whose social centrality and importance might otherwise have been missed. 
1 A multiplex centrality metric for complex social networks: sex, social status, and family

2 structure predict multiplex centrality in rhesus macaques

3 Brianne Beisner ${ }^{1,2}$, Niklas Braun ${ }^{3}$, Márton Pósfai ${ }^{4,5}$, Jessica Vandeleest ${ }^{2}$, Raissa D’Souza ${ }^{3,4,5}$,

4 Brenda McCowan ${ }^{1,2}$

$5{ }^{1}$ Department of Population Health \& Reproduction, School of Veterinary Medicine, University

6 of California Davis, Davis, CA 95616, USA.

$7{ }^{2}$ Neuroscience and Behavior Unit, California National Primate Research Center, Davis,

8 California 95616 USA.

$9{ }^{3}$ Department of Mechanical and Aerospace Engineering, University of California, Davis, Davis 10 CA 95616, USA.

$11{ }^{4}$ Complexity Sciences Center, University of California Davis, Davis, CA 95616, USA.

$12{ }^{5}$ Department of Computer Sciences, University of California Davis, Davis, California 95616, 13 USA.

Corresponding Author:

Brianne Beisner ${ }^{1,2}$

17

1089 Veterinary Medicine Dr, Davis, CA 95616, USA

18

Email address: babeisner@ucdavis.edu 
20

21

22

23

24

25

\section{Abstract}

Members of a society interact using a variety of social behaviors, giving rise to a multifaceted and complex social life. For the study of animal behavior, quantifying this complexity is critical for understanding the impact of social life on animals' health and fitness. Multilayer network approaches, where each interaction type represents a different layer of the social network, have the potential to better capture this complexity than single layer approaches. Calculating individuals' centrality within a multilayer social network can reveal keystone individuals and more fully characterize social roles. However, existing measures of multilayer centrality do not account for differences in the dynamics and functionality across interaction layers. Here we validate a new method for quantifying multiplex centrality called consensus ranking by applying this method to multiple social groups of a well-studied nonhuman primate, the rhesus macaque. Consensus ranking can suitably handle the complexities of animal social life, such as networks with different properties (sparse vs. dense) and biological meanings (competitive vs. affiliative interactions). We examined whether individuals' attributes or sociodemographic factors (sex, age, dominance rank and certainty, matriline size, rearing history) were associated with multiplex centrality. Social networks were constructed for five interaction layers (i.e., aggression, status signaling, conflict policing, grooming and huddling) for seven social groups. Consensus ranks were calculated across these five layers and analyzed with respect to individual attributes and socio-demographic factors. Generalized linear mixed models showed that consensus ranking detected known social patterns in rhesus macaques, showing that multiplex centrality was greater in high-ranking males with high certainty of rank and females from the largest families. In addition, consensus ranks also showed that females from very small families and mother-reared (compared to nursery-reared) individuals were more central, showing 
43 that consideration of multiple social domains revealed individuals whose social centrality and

44 importance might otherwise have been missed. 


\section{Introduction}

Social life is complex and multi-faceted. Members of a society interact with each other in a variety of different ways and these different behaviors are often interdependent. In animal societies, for example, individuals may spend time in proximity, groom one another, and direct aggression at or show submission to one another. Social relationships thus arise from the patterning of these different types of interactions, and similarly, social structure arises from the patterning of these relationships within a society (Hinde, 1976; Whitehead \& Dufault, 1999a). Traditional analytical approaches cannot adequately represent or quantify such multilayer complexity. Yet, given the importance of social relationships for the fitness, health and wellbeing of social animals (e.g., Akinyi et al., 2013; Silk et al., 2009, 2010; Cameron, Setsaas \& Linklater, 2009; Stanton \& Mann, 2012), accurate quantification and representation of this type of social complexity is critical to advance our understanding of the selective forces acting on individuals, the impact individuals may exert on their conspecifics, and the overall social structure of animal societies. Here we present a new approach for quantifying multilayer network centrality, called 'consensus ranking' (Pósfai et al., 2019), and illustrate its utility for uncovering novel information about individuals' social roles and social structure using rhesus macaques (Macaca mulatta).

\section{Social Network Analysis for Social Complexity}

Animal societies are complex systems; they are composed of multiple individuals that interact in a variety of contexts using multiple behaviors which generates higher-order emergent properties (e.g., hierarchies; social structure) (Bradbury \& Vehrencamp, 2014; Fisher \& Pruitt, 2019). The recent surge in the application of social network analysis (SNA) to study animal social relationships and social structure reflects this recognition (Flack et al., 2006; Sundaresan 
68 et al., 2006; Wey et al., 2008; Ramos-Fernández et al., 2009; Beisner et al., 2011a; McCowan et

69 al., 2011; Pinter-Wollman et al., 2011; Brent et al., 2013; Pasquaretta et al., 2014; Ilany, Booms

70

71

72

73

74 \& Holekamp, 2015). SNA is well-suited for examining social complexity as it offers a way to mathematically represent not just direct relationships but indirect ties among conspecifics, thus quantifying the web of indirect social connections in which members of society are embedded.

Most empirical work examining social networks has focused on single network layers.

Certainly, analyses of single network layers have offered valuable insights. For instance, network analysis has revealed examples of the social diffusion of behavior (Aplin et al., 2012; Allen et al., 2013), the impact of individual centrality and network modularity on infection risk and transmission (Griffin \& Nunn, 2012; VanderWaal et al., 2013, 2014; Balasubramaniam et al., 2016), key aspects of species social structure (Lusseau, 2003; Sundaresan et al., 2006; PinterWollman et al., 2011; Beisner et al., 2016), and the impact of key individuals on social structure (Lusseau \& Newman, 2004; Flack et al., 2006). Yet, these social patterns and processes are more complex than what can be represented by a single network.

\section{Multilayer Networks}

A multilayer network is composed of two or more different networks (for example, each representing a different type of interaction) that may be linked to each other through inter-layer edges (De Domenico et al., 2013; Bianconi, 2018). A multiplex network is a special type of multilayer network and inter-layer edges connect the same actor in different layers, which generally equates to different layers representing different sets of behavioral interactions among the same set of individuals. Given that members of a society interact in different ways using different social behaviors, each interaction type can represent a different layer of a multiplex social network. Multilayer network approaches unify information across separate interaction 
91 networks or social domains (Barrett, Henzi \& Lusseau, 2012; Finn et al., 2019) to address

92 questions about both individual-level (e.g., individual social role) and higher-order (e.g., group-

93 level social structure) social patterns. For instance, using a single network layer to identify the

94 individual(s) of greatest influence, importance, and/or centrality runs the risk of missing truly

95 influential individuals by relying on incomplete social information. Similarly, higher-order social

96 structure results from the interplay among multiple different social domains, e.g., dominance and

97 kinship, and their joint consideration is essential for accurately characterizing species social

98 structure (e.g., Thierry, 2004). In fact, a recent investigation of what causes social instability in

99 captive social groups of macaques found that socially stable groups were all characterized by the

100 same pattern of interdependence between the aggression network and the status signaling

101 network, whereas the groups that succumbed to social collapse exhibited deviations from this

102 pattern (Beisner et al., 2015), indicating that social stability emerged from a complex relationship

103 between multiple network layers.

Much evidence already points to multilayer social effects on key outcomes related to

105 fitness and health. For instance, the composite sociality index (CSI), which is calculated using

106 both proximity and grooming relationships, is associated with greater infant survival (Silk et al.,

107 2009) and longevity (Silk et al., 2010) in female baboons. Infection risk and transmission of

108 bacterial infectious agents has been linked to multiple behavioral networks in both wild meerkats

109 and captive macaques, with both tuberculosis and Shigella infection risk, respectively, being

110 jointly associated with position in a dominance network and an affiliation network (Drewe, 2010;

111 Balasubramaniam et al., 2016). In addition, fecal E. coli transmission in captive macaques is

112 jointly associated with grooming and huddling network centrality (Balasubramaniam et al.,

113 2019). However, examining behavioral networks separately fails to acknowledge the complex 
114 interdependence between different interaction layers, and composite measures such as CSI do

115 not factor in indirect social connections like many network measures do. Furthermore,

116 aggregating multiple types of interactions into a single weighted network does not preserve

117 layer-specific topology and dynamics or interdependencies across interaction layers which may

118 be important for understanding higher-order social structure or the influence of specific

119 individuals (De Domenico et al. 2015, Halu et al. 2013). Multilayer network techniques offer a

120 different way to look at 'composite' measures of social behavior that explicitly incorporate

121 interdependence across different types of interactions, indirect social connections, and the unique

122 dynamics of each contributing layer. Thus, the impact of complex social processes on individual

123 fitness may be better understood and characterized by using multilayer approaches such as

124 multiplex centrality.

Multiplex centrality can further give insights into an individual's social position/ role

within society. Individuals are heterogeneous in their social role, impact on others, and relative

importance to the maintenance of social structure. Some individuals, for instance, can play a

disproportionately important role (or have disproportionately large impact on the lives of others),

network layer is unlikely to fully represent the nature or complexity of this role. For example,

both alpha males and matriarchs are considered keystone individuals in some societies, and their

\& Sharpe, 1966; Flack, de Waal \& Krakauer, 2005; McCowan et al., 2011; von Rohr et al.,

power (Flack \& Krakauer, 2006; Beisner et al., 2016), be popular grooming partners (Sade, 
137 Fedigan, 2018). Similarly, matriarchs may possess knowledge of key resources or potential

138 threats (McComb et al., 2001; McComb Karen et al., 2011; Brent et al., 2015), contribute to

139 survival of grandchildren (Hawkes, O’Connell \& Blurton Jones, 1997; Kachel, Premo \& Hublin,

140 2011), or uphold the stability of their family's social status (Beisner et al., 2011a; Wooddell et

141 al., 2016). Given the complexity that can underlie keystone status, multilayer approaches for

142 understanding centrality may better characterize the layers contributing to an individual's

143 keystone status and may identify keystone individuals that would otherwise have been missed.

144 Multilayer Approaches

Methods to perform multilayer network analysis have only recently been developed, and their application to understanding animal social relationships and social structure has only just begun (Barrett, Henzi \& Lusseau, 2012; Chan et al., 2013; Beisner et al., 2015; Silk et al., 2018;

148 Finn et al., 2019). Some approaches focus on network-level patterns such as characterizing interdependence between network layers (Barrett, Henzi \& Lusseau, 2012; Chan et al., 2013; Beisner et al., 2015) and others focus on individual or node-level position such as centrality or clustering (Barrett, Henzi \& Lusseau, 2012; De Domenico et al., 2015; Smith-Aguilar et al., 2018). Here we focus on individual-level centrality in a multilayer network.

154 (i.e., node) is central versus peripheral in the network. Centrality in single and multilayer networks can be assessed using a variety of different metrics, including degree (one's direct connections), betweenness (the tendency to connect individuals who are otherwise weakly connected), eigenvector centrality (the extent to which one is connected to well-connected refers to individuals or nodes that are well-connected not simply in a single layer, but well- 
160 connected across multiple network layers. Methods for quantifying centrality in a multiplex

161 network range from simple (e.g., aggregation of connections across layers regardless of

162 interaction type) to complex (encode connections within and between layers using a multi-

163 dimensional tensor) (e.g., Barrett, Henzi \& Lusseau, 2012; De Domenico et al., 2015). For

164 instance, 'Multiplex PageRank' is a method which works by calculating PageRank centrality on

165 one layer and then biasing the PageRank on the next layer by allowing the centrality of a node in

166 the first layer to be influenced by its centrality in the second layer (Halu et al., 2013). The open-

167 source software MuxViz allows you to calculate multilayer generalizations of multiple different

168 types of centrality such as degree and eigenvector centrality (De Domenico, Porter \& Arenas,

169 2015), and between-layer connections are represented by placing an edge between each node

170 and itself across all pairs of layers (Kivelä et al., 2014; De Domenico et al., 2015).

172 PageRank (Bianconi 2018; De Domenico et al. 2015; Halu, et al. 2013) assume that all layers represent similar types of relationships and have similar structure, and some are restricted in

174 practice to only two layers (e.g., multiplex PageRank). For instance, an airline transportation 175 network, in which each layer represents a different airline company, is a common example of a 176 multilayer network in which the meaning of a link in each layer is the same (i.e., a flight between 177 two cities in the network) and the network structure is similar (e.g., each airline company has one 178 or more 'hub' cities which operate more flights than the other cities in the network). Yet animal 179 social networks are frequently composed of layers with significant structural differences (e.g., dominance network links are directed whereas affiliative network links may not be; proximity networks are dense, with many of the total possible links being present, whereas contact interaction networks are much more sparse, with far fewer links present; (Smith-Aguilar et al., 
183 2018)). Such structural differences across layers may mean that, for example, eigenvector

184 centrality is best for measuring centrality in a dominance interaction layer with clear 'hubs' but

185 betweenness centrality is ideal for measuring centrality in an affiliation layer with evidence of

186 familial/kin clustering. No existing method for quantifying multilayer centrality simultaneously

187 satisfies all requirements: (i) allowing different metrics of centrality on different layers (degree

188 centrality on one layer, betweeness centrality on another), (ii) allowing significant structural

189 differences between layers (directed-undirected, sparse-dense), and (iii) including more than two

190 layers. Here we apply a new method for measuring multiplex centrality, called consensus

191 ranking (Pósfai et al., 2019), to multiple social groups of a well-studied nonhuman primate, the

192 rhesus macaque, to examine whether attributes of individuals (sex, age, dominance rank and

193 certainty) or socio-demographic factors (matriline size, mother- vs. nursery-rearing history) are

194 predictive of their overall centrality or influence in the social network. We also illustrate the

195 utility of this method for uncovering novel information about social roles and social structure by

196 comparing the findings from the analysis of multilayer consensus rankings to the analyses of

197 single network layers.

198

199

200

201

202

203

204

205

Rhesus Macaque Societies as a Testbed for Multilayer Model Development

An important step in developing and validating a new multilayer network metric is to

identify a sufficiently well characterized and complex model testbed. Rhesus macaques (Macaca mulatta) are just such a model species - their behavior and social structure are both complex and well-studied. Rhesus macaque social networks have been studied with regard to social style (Sueur et al., 2011; Balasubramaniam et al., 2018), genetic variance (Brent et al., 2013), health outcomes (Vandeleest et al., 2016), and group stability (McCowan et al., 2011; Beisner et al., $2015,2016)$. Furthermore, macaque social structure is thought to arise from specific 
206 combinations of aggression intensity, dominance asymmetry, and rates of post-conflict affiliation

207 (Thierry, 2004), an idea that invokes multilayer social structure.

208 Study System and Predictions

The existing knowledge of rhesus macaques is rich enough to generate clear predictions

210 about how attributes and socio-demographic factors influence multiplex centrality. Rhesus

211 macaque societies have clear dominance hierarchies and strong kinship relationships among

212 females (Thierry, 2004). Sex differences in rank acquisition patterns shape the roles that males

213 and females play in multiple interaction networks. Male-biased dispersal and female philopatry

214 (Drickamer \& Vessey, 1973; Sugiyama, 1976) result in temporally stable, heritable dominance

215 relationships among females (Sade, 1969) and more labile dominance relationships among males

216 (Berard, 1999). Since dominant animals are expected to be central in single interaction layers

217 heavily influenced by dominance rank (e.g., aggression, submission), we predicted they would

218 also be central in the multiplex network. Furthermore, the effect of dominance on multiplex

219 centrality may differ by age-sex class because high-ranking adult males often play keystone roles

220 - they frequently police the conflicts of group members (Bernstein \& Sharpe, 1966; Beisner \&

221 McCowan, 2013) and such policers receive a disproportionate number of subordination signals

222 (Beisner et al., 2016). Specifically, we predict high-ranking males and older males will be more

223 central in the multiplex network than lower-ranking or younger males.

Another aspect of dominance that may influence multiplex centrality is dominance certainty. Dominance certainty reflects the average level of certainty (or ambiguity) in an

226 individual's dominance relationships and is based upon pathway consistency in aggression

227 networks (e.g., Vandeleest et al., 2016). Low dominance certainty reflects the potential for rank

228 mobility (i.e., gain or lose rank) and may impact multiplex centrality, particularly for males 
229 because rank is more labile. For example, a dominant male at risk of losing his rank may be an

230 unpopular grooming partner and he may receive few subordination signals and police conflicts

231 infrequently. We predict that high-ranking males with high dominance certainty will have greater

232 centrality in the multiplex network than high-ranking males with low dominance certainty.

Third, family structure is likely to influence centrality as the presence of kin shapes the

patterning of social interactions because the benefits of cooperating with kin are typically greater family size. Female macaques preferentially affiliate and interact with close kin (Gouzoules \& Gouzoules, 1987; Bernstein, Judge \& Ruehlmann, 1993). We predict that females from larger families will have greater multiplex centrality because they have more kin partners with whom to interact than individuals from smaller families.

Finally, we examine rearing history because among captive macaques, nursery-rearing is known to impact brain development and social behavior (Winslow et al., 2003; Suomi, 2006). Nursery-rearing (NR) refers to individuals that were removed from their mothers during infancy, typically at birth or around weaning age ( $\sim 6$ months) and housed with same-aged peers. We expect NR to impact social behavior in a cognitively sophisticated social species such as rhesus macaques because much social behavior is learned, initially through an infant's attachment to its mother which influences a wide range of social and physiological outcomes (Capitanio et al., 2006). Compared to their mother-reared (MR) counterparts, NR infants explore and play less and exhibit more extreme behavioral and physiological responses to social separation at 6 months of age (Suomi, 2006). As they mature, NR monkeys become less affiliative and more aggressive than their MR peers (Winslow et al., 2003; Suomi, 2006), and spend more time alone (Winslow et al., 2003). These behavioral differences have been linked to alterations in neural and endocrine 
252 systems (Clarke, 1993; Sánchez et al., 1998; Winslow et al., 2003; Capitanio et al., 2006).

253 However, while the evidence to date suggests that NR should impact individuals' abilities to

254 navigate their social environment, most studies of NR vs. MR differences are examined in pair-

255 housed or small group housed animals up to 3 years of age, as opposed to large social groups of

256 adult animals. Of the research that has been done on social groups, results are mixed. Although

257 NR individuals may be lower-ranking than MR individuals when housed together in social

258 groups (e.g., Bastian et al., 2003; Dettmer et al., 2017), some studies show no discernible

259 differences related to rearing (Bauer \& Baker, 2016). We predict NR individuals will have lower

260 multiplex centrality than MR.

261 Materials \& Methods

262 Study Subjects

263 Behavioral network data were collected from seven captive social groups of rhesus

264 macaques (Macaca mulatta) housed in half-acre (0.2 ha) outdoor enclosures at the California

265 National Primate Research Center in Davis, CA. Groups varied in size, age structure, number of

266 matrilines, and the rearing history of animals (Table 1). Housing conditions were similar for all

267 groups. Each enclosure contained multiple A-frame structures, suspended barrels, swings, and

268 perches and animals were free to interact as they chose. Animals were fed a standard diet of

269 monkey chow twice per day at approximately $0700 \mathrm{~h}$ and between 1430 and $1530 \mathrm{~h}$. Fresh fruit

270 or vegetables were provided once per week and seed mixture was provided daily. Water was

271 available ad libitum. All research reported here adhered to the recommendations in the Guide for

272 the Care and Use of Laboratory Animals of the National Institutes of Health, and the laws of the

273 United States government. This research was approved by the University of California, Davis

274 Institutional Animal Care and Use Committee, protocol \#18525. 
277 formation. The remaining 24 subjects were mother-reared until $3-11$ months of age $($ mean $=6.9$

278 months) and housed with one or more peers until the time of group formation. Nursery-reared subjects were older, on average, than other subjects (NR subjects: mean $=15.0$ years, range $=9$ -

21 years; MR subjects: mean $=6.8$ years, range $=3-29$ years) because most of them were the

281 founding members during new group formations.

\section{Behavioral Data Collection}

for four consecutive weeks) by a team of two observers. Data were collected for 6 hours per day on 4 days per week from $0900-1200 \mathrm{~h}$ and 1300-1600 h. Previous analyses have confirmed that this frequency of data collection is sufficient to construct reliable networks (Balasubramaniam et from the baseline phase of this study. interactions, we used an event sampling design to collect all instances of agonism, including both aggression and status signaling. Agonistic events were recorded as a series of dyadic interactions in which observers documented the identities of all participants, the type of aggressive or submissive behavior used by each, and the sequence of these interactions. Aggressive behavior was categorized according to severity and included threat (e.g., open mouth stare, brow flash), mild aggression (threat and follow, lunge, push, slap, chase $<6$ meters), moderate aggression 
298 when a third-party enters, or intervenes upon, the conflict. Intervention was defined as a third-

299 party entering an on-going conflict by aggressing or approaching one or both participants. More

300 specifically, impartial interventions, which are sometime referred to as policing interventions

301 (Flack, Krakauer, \& deWaal, 2005; Beisner \& McCowan, 2013), were those in which the

302 intervener treated both participants the same, either by approaching or aggressing them. Status

303 signals were defined as a submissive response to a peaceful (i.e., no overt aggression) approach

304 and included silent-bared teeth display (SBT), freeze/turn away, or move away (i.e.,

305 displacement).

For affiliative interactions, we used a scan sampling design to collect grooming and

307

308

309

310

311

312

huddling interactions. Scan samples were conducted every 20 minutes during data collection hours, proceeding from one side of the enclosure to the other (e.g. from left to right). Grooming was defined as an animal cleaning or manipulating the fur of another individual. Huddling was defined as the occurrence of all forms of body-contact e.g., ventral contact or an embrace between two individuals. A high level of inter-observer reliability was maintained across all observers for all behavioral data collection (Krippendorf's alpha $\geq 0.85$ ).

\section{Dominance Rank Calculation}

Dominance ranks were calculated from dyadic aggressive interactions using the Perc package in $\mathrm{R}$, a method which combines dominance information from direct interactions and indirect network pathways into the win-loss matrix (Fushing et al., 2011; Fujii et al., 2015). For instance, a network pathway from $\mathrm{A}$ to $\mathrm{B}$ to $\mathrm{C}$ (i.e., A defeats $\mathrm{B}, \mathrm{B}$ defeats $\mathrm{C}$ ) suggests that $\mathrm{A}$ is likely dominant to $\mathrm{C}$; the imputed dominance information from network pathways (i.e., each path is a fraction of a win) is added to the win-loss matrix. Since dyadic aggression data were used to calculate both dominance ranks and aggression layer centrality, these dominance ranks could not 
321 be used in the analysis of aggression layer centrality (see Network Layer Construction and

322 Statistical Analyses below). However, study groups were part of a larger study involving social

323 perturbations, and aggression data were available for the experimental phase, which immediately

324 followed the baseline phase and was identical in duration and data collection design. We

325 therefore calculated a second set of dominance ranks from the experimental phase for analyzing

326 aggression layer centrality. We imputed the ranks of animals that were experimentally removed

327 from the group due to the social perturbation $(\mathrm{N}=1-19$ animals per group; median $=2$ animals $)$

328 by assuming that their position in the hierarchy was the same as before removal. Dominance

329 rankings calculated from the baseline and experimental phases were highly correlated for all

330 study groups (mean Spearman's $r=0.967$, range: $0.958-0.976$ ).

\section{Network Layer Construction}

Five behavioral network layers were chosen to represent multiple key facets of rhesus macaque social structure and social life: (1) dyadic aggression (including all levels of severity), (2) status signaling (i.e., displacements and subordination signals), (3) impartial conflict interventions (aka policing), (4) grooming, and (5) huddling. Layers for dyadic aggression and status signaling were chosen because rhesus macaque society is hierarchically structured.

337 Furthermore, rhesus macaques in this captive population have been found to exhibit a clear relationship between the dyadic aggression and status signaling network layers which, when it erodes or changes significantly, is associated with social collapse (Beisner et al., 2015). The impartial conflict policing layer was chosen because impartial interventions, performed most

341 frequently by powerful individuals (e.g., alpha and/or beta males), are important for the control 342 of within group conflict and maintenance of social stability (Bernstein \& Sharpe, 1966; Flack, 343 Krakauer \& de Waal, 2005; McCowan et al., 2011). Furthermore, the connections between 
344 intervener and combatants may reflect more than differences in social power but also valued

345 social relationships, as there is evidence that policers defend victims (Beisner \& McCowan,

346 2013). The layers for grooming and huddling were chosen because of the importance of

347 affiliative interactions for the maintenance of social cohesion (Lehmann, Korstjens \& Dunbar, 348 2007).

Each layer differed in its properties. Aggression, status signaling, and impartial policing layers were treated as directed networks because edge direction contains important information

351

352

353

354

355

356

357

358

359

360

361

362

363

364

365

366

about social dominance that yield emergent structures such as the dominance hierarchy and social power distribution (Beisner \& McCowan, 2013; Beisner et al., 2016). The layers for grooming and huddling were treated as undirected networks because links represent the presence of an affiliative relationship (rather than the direction of a given affiliative interaction) and connectivity reflects broad social cohesion (e.g, grooming can be directed up the hierarchy (Seyfarth, 1977), toward kin or close allies (Sade, 1972b), yet all these interactions facilitate social cohesion).

\section{Multilayer Consensus Ranking}

To generate consensus rankings, we selected an appropriate centrality metric for each layer. Dominance-based layers (i.e., aggression, status signaling, policing) were measured using centralities based on finding hubs such as eigenvector (Bonacich, 2007) and degree centrality, whereas affiliative layers (i.e., grooming, huddling) were measured using betweenness centrality which is based on cohesion. Eigenvector centrality was used in the aggression layer because it is effective at determining hierarchy in connected networks. Degree centrality was chosen for the status signaling (in-degree) and policing (sum of in- and out-degree) layers because these networks were sparser and not always fully connected (Table 2). For the policing layer, both out- 
367 going and in-coming edges contained valuable information with regard to power differences and

368 valued social relationships. Betweenness centrality was chosen because it better reflects cohesion

369 in our study system's affiliation networks, which can include functionally different types of

370 interactions in the same layer (e.g., grooming among kin, which can create clustering structure,

371 and 'economic' grooming, which may connect across matrilines). All network layers were

372 weighted, and edge weights were calculated as frequencies of interaction during the study period.

374 the different network layers by first generating a ranking of importance for each layer, i.e., in

375 each layer, individuals are ranked 1 to a maximum of $N$, from largest centrality to smallest

376 centrality (where $N$ is the number of nodes). We treat the cases when two or more nodes share

377 the same centrality value by assigning them the same rank. For example, if individuals A, B, and

$378 \mathrm{C}$ have centralities $0.4,0.4$, and 0.2 , respectively, then $\mathrm{A}$ and $\mathrm{B}$ are ranked first and $\mathrm{C}$ is ranked

379 second. Then, a rank aggregation algorithm is used to find the most central nodes in the

380 multiplex network (Arrow, 2012). In general, a rank aggregation method takes two or more

381 rankings of the same items as an input and produces a consensus ranking. The specific definition

382 of consensus ranking depends on the rank aggregation algorithm of choice. Here, we focus on

383 the widely-used and intuitive Borda count (de Borda, 1781; Dwork et al., 2001). average rank in the individual layers. More specifically, let $b_{\alpha, i}$ be rank of node $i$ in layer $\alpha$; then the score assigned to node $i$ is

$387 b_{i}=\frac{1}{L} \sum_{\alpha=1}^{L} b_{\alpha, i}$,where $L$ is the number of layers in the multiplex. Borda count then assigns a 
388 consensus rank to each node based on the scores $b_{i}$ : The node with the lowest score is

389 determined to be the highest overall ranked candidate; the node with the second lowest score is

390 the second overall ranked candidate; and so on.

A rank aggregation algorithm is beneficial for quantifying multilayer centrality because

392

393

394

395

396

397

398

399

400

401

402

403

404

405

406

407

408

409

410

(a) it provides a means of combining information across layers with different topologies by

allowing different centrality metrics for each layer, and (b) all layers are weighted equally so that no single layer has greater influence than another. Often the actual importance of each layer relative to others is unknown or speculative at best, and the weight assigned to each layer in an aggregate network measure is either arbitrary or based on the size of the network (e.g., edge count, average degree). One potential weakness, however, is that the ranking in each layer is done separately and therefore does not incorporate the multiplexity of interdependence across layers. For instance, an individual connected to the same 10 individuals in layers A and B will be higher ranked by consensus ranking than an individual connected to a different set of six individuals in layers A and B (12 unique individuals overall).

\section{Rank tiers within layer}

The values of a centrality metric are unevenly distributed, typically the centrality difference between high-ranked nodes is large, while the centralities of low-ranked nodes are almost indistinguishable (Figure 1). This information is lost if nodes are placed in a linear ordering, prompting the question: when do we assign a different rank to two nodes? There is no established answer to this question. Here, instead of assigning an ordinal rank to each node, we place the nodes into tiers using one dimensional hierarchical clustering (Defays, 1977; Müllner, 2011). At the start of the procedure each node is placed in its own cluster and the distance between each node is the absolute value of their centrality. Then we merge the two closest nodes 
411 into a cluster and iteratively repeat this procedure until all nodes are joined. To measure the

412 distance between two clusters with more than one node we use complete linkage, that is their

413 distance is given by the maximum distance between any pair of nodes in the two clusters. This

414 use of complete linkage ensures that we find tiers with a relatively similar spread in values

415 (Everitt et al., 2011). The process of tiering distinguishes groups of nodes with similar centrality, 416 while maintaining a ranked structure.

417 Hierarchical clustering does not produce a single grouping of the nodes but provides a

418 hierarchy of possible clusters represented as a hierarchical tree (Figure 1a). Cutting the tree at 419 different heights yields tiers at different resolutions. The choice of the cut is somewhat subjective 420 and is typically decided based on data heuristics or the requirements of the application. We chose 421 the location of the cut considering how much of the variance of the un-tiered centrality values is 422 explained by the tiered centrality values (i.e., a 90\% threshold means we cut the tree producing 423 the minimum number of tiers such that the explained variance is at least $90 \%$ ). The explained 424 variance is quantified by $r^{2}$, where $r$ is the Pearson correlation between the original centralities 425 and their tiered values (all nodes in a tier are assigned the mean centrality of the nodes in that 426 tier). The threshold value affects the number of tiers we identify: for one study group, a $90 \%$ 427 threshold produces 4-8 tiers per layer, while a 99\% threshold yield 7-12 tiers per layer. We chose 428 a 99\% threshold for all layers and groups because (a) it produced enough layers to sufficiently 429 differentiate individual monkeys within a group for the purposes of our analysis (e.g., 100 430 monkeys spread across 7-12 rank tiers) and (b) it mapped well onto visually-obvious break 431 points in the data. For validation purposes, we also analyzed the data using a $99.5 \%$ threshold to 432 determine if results were robust to number of tiers. Tier identification and Borda rank 433 calculations were run using Python code developed by co-authors NB and MP. 
434

435

436

437

438

439

440

441

442

443

444

445

446

447

448

449

450

451

452

453

454

455

456

\section{Statistical analyses}

To estimate the extent to which different layers contain similar versus different

information about individuals' social position within the social network, we first examined the correlation between each pair of layers for each study group. Pairs of layers with higher

Spearman correlations contain more similar information. We then used a recently-developed machine learning clustering method, Data Mechanics (Fushing \& Chen, 2014; Guan \& Fushing, 2018), to further examine similarity across layers. Data Mechanics is a data-driven method that can detect clustering in multiple dimensions (i.e., clustering on rows and columns of a multivariate data set) without relying on assumptions of linearity, making it ideal for use with multivariate data derived from complex social systems. The ordering of the rows and columns are shuffled alternately for several iterations to reveal blocks of animals with similar values across the five layer rankings and sets of layers with similar values across the different animals. Shuffling occurs using principles from thermodynamics to assign "energy" to the organization of the network matrix. Network matrices with the lowest energy state are selected as the best ordering for these blocks of subjects (Guan \& Fushing, 2018). Data Mechanics was applied to the data set of $\mathrm{N}$ animals $\times 5$ layer rankings for each group, and the hierarchical clustering tree on the columns was examined to determine which two layers showed the greatest similarity (i.e., clustered together). Data Mechanics was run in R using code obtained from Dr. Hsieh Fushing.

Next, we fitted generalized linear mixed models (GLMMs) to the consensus ranking, with group as a random effect. The consensus rankings ranged from 1 to between 25 and 30 , across the seven study groups, with the lowest values corresponding to the individuals with greatest multiplex centrality. These rankings produced a right-skewed data distribution with few animals having Borda ranks near 1 and more animals having Borda ranks $>20$. We reversed these 
457 rankings to range from 0 (lowest centrality) to between 24 and 29 by subtracting each Borda rank

458 from the maximum value in the group which produced an outcome distribution that could be

459 modeled using a Poisson or Negative Binomial family model. Tiers were present in the

460 consensus rankings, and the more populated tiers occurred at the bottom of the consensus

461 ranking (i.e., many individuals had low multiplex centrality). Therefore, the distribution of

462 reversed consensus ranks could be suitably modeled using a Negative Binomial family

463 regression model. Fixed effects in these models included animal age (in years), sex (male or

464 female), dominance rank (the percentage of group members outranked by each subject),

465 dominance certainty (observed range: $0.69-0.98$ ), matriline size (both numerical and

466 categorical versions were tried), rearing history (mother-reared vs. nursery-reared) as well as

467 some interactions between these terms based upon our predictions (e.g., rank $\times$ sex). Dominance

468 certainty is a network-based measure of one's 'fit' within the hierarchy and is calculated as the

469 average level of dominance relationship certainty (based on directional consistency of pathways

470 in the aggression network) for each animal in the group. It ranges from 0.5 (ambiguous) to 1.0

471 (certain) and shows a roughly U-shaped relationship to dominance rank (Vandeleest et al. 2016).

472 To facilitate interpretation of model coefficients, dominance certainty was transformed

473 (subtracted from 1.0) so that a value of 0 reflects complete certainty and 0.5 reflects complete

474 ambiguity. With respect to calculating matriline size, individuals descended from the same

475 female common ancestor at the time of group formation were considered part of the same

476 matriline. Once all models were fitted, we used an Information Theoretic approach to select a

477 candidate set of models to interpret (Burnham \& Anderson, 2002; Burnham, Anderson \&

478 Huyvaert, 2011). We calculated AICc scores (Akaike Information Criteria, corrected for small

479 sample size) for each model. We included in the candidate set all models within 4 AICc points of 
480 the best model, as this threshold has a high probability of including the best K-L model (i.e., the

481 model that minimizes Kullback-Leibler information loss and thus best approximates reality

482 (Burnham, Anderson \& Huyvaert, 2011) while also yielding a reasonable number of models to

483 interpret. Model weights were calculated for all models in the candidate set to facilitate

484 understanding of which models have the most support. All GLMMs were run in R using the

485 glmm $A D M B$ package (Fournier et al., 2012).

Additional GLMMs were fitted to the individual network layers that showed the highest correlation to the consensus ranking (i.e., aggression, status signaling, and grooming layers) to determine whether patterns in the relationship between individual attributes and network centrality are different in the multiplex compared to its component layers. We applied the same Information Theoretic approach, described above, for these analyses.

Social network data are inherently non-independent, meaning network measures violate assumptions of data independence, and p-values derived from GLMMs cannot be trusted (Croft et al., 2011; Farine, 2017). To address this, we performed node-based network randomizations on all network layers for all study groups. Node-based randomizations shuffle the attributes of the nodes in the network (e.g., sex, age, dominance rank), which is the relationship we wish to test, and preserves the biologically relevant network structure of the species (Farine \& Whitehead, 2015). After each randomization, we recalculated the network centrality rankings and fitted the same GLMMs to the randomized versions of centrality as were fit to the observed data. Specifically, 1000 randomizations were performed separately for each top model being evaluated

500 (1-5 models per outcome variable; see Results), which generated a distribution of model 501 coefficients (one distribution for each term in the model). We used these distributions to 502 calculate significance for each model coefficient for the observed data. Using two-tailed values, 
503 the observed coefficient is significantly different from random at $p=0.05$ if fewer than $2.5 \%$ of

504 the random values are larger than the observed coefficient or if greater than $97.5 \%$ of the random

505 values are larger than the observed coefficient. All randomizations were performed in R using

506 code developed by co-author MP.

Finally, to determine whether the results from the analysis of the consensus rankings

were robust to the threshold used to create rank tiers within each layer, we repeated our analyses

with the consensus rankings from a higher threshold (99.5\% as opposed to the original $99.0 \%)$.

510 Briefly, the analyses of this second set of consensus rankings produced the same best-fit models

511 as the original analysis but with somewhat greater uncertainty because the strength of evidence

512 for the best model was 0.68 as compared to 0.80 in the original analyses. These results are

513 presented in Supplementary Information files.

\section{Results}

Pairwise layer correlations

Correlations across pairs of the five layers were relatively consistent across study groups.

517 The strongest positive correlations were found between the aggression and status signaling layers

518 (range: $0.74-0.88$; Figure 2), which is unsurprising given that both aggressive and status

519 signaling interactions are guided by dominance relationships. The Policing layer showed a more

520 variable positive correlation with the Aggression (range: $0.34-0.63$ ) and Status signaling

521 (range: $0.13-0.53$ ) layers, which can arise when some high-ranking individuals do not police

522 conflicts (Beisner and McCowan 2013; Beisner et al. 2016). The Huddling layer showed little to

523 no correlation with any layer except Grooming (range: $0.19-0.45$; Figure 2). The Grooming

524 layer showed a variable correlation with the Aggression and Policing layers - moderate in some 
525 groups and quite low in other groups. In sum, although some pairs of layers showed a strong

526 correlation, each layer contributed unique information regarding an individual's position.

527 Clustering of layers and potential layer redundancy

528

529

530

531

532

533

534

535

536

537

538

539

540

541

542

543

544

545

546

Hierarchical clustering trees for each study group agreed with the pairwise layer correlations. The aggression and status signaling layers were the two most similar layers, and they were consistently placed in the same column cluster (e.g., Figure 3), while the other network layers showed more distant relationships. Although the similarity between the aggression and status signaling layers might suggest redundancy, prior multilayer analyses conducted on aggression and status signaling networks from CNPRC social groups demonstrate a critical interdependence between these networks that would not arise if they were redundant (Beisner et al., 2015). We therefore kept all five behavioral network layers in the calculation of consensus rankings.

Attributes and socio-demographic factors associated with consensus rank

GLMM analyses of the consensus ranking revealed two models in the candidate set, with the best model having $79.6 \%$ of the model weight (best-fit model: AICc $=3635.3$, compared to second-best model dAICc $=2.7$ ). As the strength of evidence for Model 1 was nearly $80 \%$, we report in detail only the results of Model 1 but provide outputs for both models in Table 3 . In general, dominant individuals had higher consensus ranks than subordinates (Figures 4 \& 5A). Interactions among sex, dominance rank, and dominance certainty showed that among males (but not females) the effect of dominance rank on consensus rank depended upon the relative certainty (or ambiguity) of the male's dominance rank (Figures $4 \& 5 \mathrm{H}$; Table 3 ). Having greater dominance certainty reduced multiplex centrality in low-ranked males whereas having low 
547 dominance certainty (i.e., greater ambiguity surrounding your fit in the hierarchy) increased

548 multiplex centrality in low-ranked males. In contrast, among high-ranked males, high dominance

549 certainty was associated with higher consensus rank (Figure 5G; Table 3). Matriline size

550 category also influenced centrality, and its effect differed for males versus females. The

551 consensus ranks of females from medium-sized families (6-10 members) were 1.2 times lower

552 than females from small families (1-5 members) and large families $(11+$ members, $\mathrm{p}<0.001)$; for

553 example, for females of average dominance certainty and rank, the model-predicted consensus

554 rank is 20.0 for females from small and large families compared to 16.7 for females from

555 medium families (Figure 5E-F). Matriline size did not affect multiplex centrality among males.

556 Finally, mother-reared subjects had higher consensus ranks than nursery-reared subjects (Figure

557 5D; Table 3).

558 Aggression network layer

$559 \quad$ Analyses of aggression layer centrality rank (as measured by eigenvector centrality)

560 yielded two models in the candidate set, with the Model 1 having $87.9 \%$ of the model weight and

561 Model 2 having 12.1\% (Model 1: AICc =1890.2, compared to second-best model dAIC $=4.0)$.

562 Model 1 included a 3-way interaction for dominance rank $\times \operatorname{sex} \times$ dominance certainty whereas

563 Model 2 included a 3-way interaction for dominance rank $\times$ age $\times$ dominance certainty and a

564 main effect for sex. As the strength of evidence for Model 1 was over $80 \%$, we report in detail

565 only the results of Model 1 but provide outputs for both models in Table 4. Histograms showing

566 the distributions of model coefficients from the randomizations for Model 1 are available as

567 Supplemental Information (Figure S1). As expected, dominant individuals were more central

568 (had high higher consensus ranks) than subordinate individuals. The effect of rank was strongest

569 for males with greater dominance certainty (i.e., low dominance ambiguity; Figure S2). 
570 Compared to the analyses of the consensus ranks, the factors influencing multiplex centrality

571 were similar to those influencing aggression layer centrality except that matriline size and

572 rearing history were associated with the consensus ranking but not aggression layer centrality.

573 Status signaling network layer

574 Status layer centrality rank (as measured by outdegree) was explained by a single best

575 model $(\mathrm{AICc}=1670.6$, compared to second-best model dAIC $=15.6)$ which included dominance

576 rank, sex, age, dominance certainty, and the 3-way interaction rank $\times$ sex $\times$ age. The model

577 output is provided in Table 5, and histograms showing the distributions of model coefficients

578 from the randomizations are available as Supplemental Information (Figure S3). Dominant

579 individuals were higher ranked in the status signaling network than subordinate individuals

580 similar to the analyses of consensus rank and aggression layer rank. The 3-way interaction

581 showed that the effect of age on dominance rank differed for males versus females. Among

582 females, there was no age difference in the impact of dominance rank on status signaling

583 centrality. Among low-ranking males, older males were higher ranked in the status signaling

584 network, but among the highest-ranking males, young males were higher ranked in status

585 signaling centrality than older males (Figure S4). Finally, individuals with greater dominance

586 certainty (i.e., less ambiguity) were higher ranked in the status signaling network.

\section{Grooming network layer}

Analyses of grooming layer centrality rank (as measured by betweenness centrality)

589 yielded five models in the candidate set. Model 1 had $40.4 \%$ of the model weight, model 2 had $59030.8 \%$, and the remaining three models each had 9-10\%. All five model outputs are reported in

591 Table 6, and histograms of the distributions of model coefficients from the randomizations for 
592 Model 1 are available as Supplemental Information (Figure S5). According to Models 1 and 2,

593 dominant individuals from small matrilines were higher ranked (i.e., more central) in grooming

594 than dominants from larger families, whereas subordinate individuals from large matrilines were

595 more central than subordinates from smaller families (Figure 6). In other words, the effect of

596 rank on grooming centrality was strongest for individuals from small families and weak for

597 individuals from large families. In all models, females were more central in the grooming

598 network than males. Finally, rearing history was present in Models 1 and 3 but was non-

599 significant based upon the randomizations (Model 1: $p=0.19$; Model 3: $p=0.22$ ). Thus, in

600 analyses of both the consensus rank and the grooming layer, matriline size impacted centrality,

601 but the precise relationship between matriline size and centrality differed based upon different

602 individual-level attributes. Furthermore, although rearing history was present in the best-fit

603 models for both consensus rank and grooming layer rank, it was only statistically significant for

604 consensus rank.

605

Who occupies top consensus ranks?

Our regression analyses show a strong correlation between dominance rank and

607

multilayer consensus rank (Figure 7). However, variation around this pattern revealed some

608 individuals that were more or less central than expected. For instance, the precise rank of the

609 alpha and beta males varied across groups. In six of the seven study groups the alpha male and/or

610 beta male appear in the top six consensus rank positions (Table 7). In the seventh group,

611 however, the alpha and beta males’ Borda ranks were 15 and 9, respectively. Across the seven

612 groups, there was a lot of variability in which animal was the most central individual: the alpha

613 male (group D), the beta male (groups E \& G), an adult male other than the alpha or beta (groups

614 A \& F), and an adult female from the alpha matriline other than the alpha or beta female (groups 
615 B \& C). Thus, in four groups (A, B, C, and F), the most central individual was not an alpha or a 616 beta, but another high-ranked animal.

\section{Discussion}

Our analyses demonstrate that the consensus ranking approach (Posfai et al. 2019) for quantifying centrality in a multiplex network yields valuable information about individuals' social connectivity that is both consistent with known patterns for the study species and uniquely different from centrality information from any single layer. The factors influencing rhesus macaques' multiplex centrality aligned well with predictions based upon the literature. Highranking males with high certainty of their dominance were more central than other males, females from the largest families were more central than females from medium-sized families, and mother-reared individuals were more central than nursery-reared individuals. Importantly, an individual's multiplex centrality, as calculated by our consensus ranking method, could not be reduced to the information from a single layer, as no single behavioral network layer showed perfect concordance to the consensus ranking. Our results confirm the validity of the consensus ranking method for the purposes of assessing multiplex centrality and reveal novel information. We discuss these findings in detail below. social structure, and one's dominance rank is likely to influence overall social centrality.

634 Consistent with this expectation, we found that high ranking individuals, especially high-ranking 635 males with high dominance certainty, had higher consensus ranks. In other words, they were 636 more central in the multiplex social network. The interactions among dominance rank, 
637 dominance certainty, and sex are also consistent with what is known about the study species.

638 Among rhesus macaques, dominant males are considered keystone individuals because they

639 police group conflict (Bernstein \& Sharpe, 1966; McCowan et al., 2011; Beisner \& McCowan,

640 2013), receive a disproportionate number of subordination signals (Beisner et al., 2016), and are

641 often central in grooming networks (Sade et al., 1988; McCowan et al., 2011; Sueur et al., 2011).

642 However, single layer analyses did not uniformly capture the greater centrality of high-ranking

643 adult males with high dominance certainty. While the best model of aggression layer centrality

644 showed the greater centrality of high-ranking males with high dominance certainty, the status

645 signaling layer analysis showed that subadults with high dominance rank were more central than

646 high-ranking adults. Subadults' greater centrality in the status signaling layer compared to the

647 multiplex network was likely influenced by of a lack of centrality information derived from the

648 policing and/or grooming networks. For instance, whereas high-ranking adult males police

649 conflicts among group members (Bernstein \& Sharpe, 1966; McCowan et al., 2011; Beisner et

650 al., 2012, 2016), high-ranking subadult males are often natal males from the alpha family

651 (Koford, 1963; Tilford, 1982; Beisner et al., 2011b), and these males are less effective conflict

652 policers (Beisner et al., 2012; Jackson et al., 2012).

653 Our results also showed that, among low-ranking males, having low dominance certainty

654 (i.e., greater ambiguity regarding his fit within the dominance hierarchy) improved multiplex

655 centrality, and this makes sense because such males likely stood to gain rank, making their

656 calculated rank an inaccurate reflection of their current status and thus less useful for estimating

657 multiplex centrality. Indeed, the relative certainty or stability of a male's dominance rank can

658 affect the relationship between social status and health in some nonhuman primates (Sapolsky,

659 1992; Vandeleest et al., 2016) so its importance for understanding the relationship between 
660 social status and multiplex centrality is not unexpected. Finally, we note that although

661 dominance rank was a consistent predictor of centrality in each of the individual network layers,

662 the greater centrality of high-ranking males with high dominance certainty is not trivial because

663 sex and dominance certainty had inconsistent effects across single network layers (e.g., males

664 being central in aggression and status, females being central in grooming and huddling). These

665 results highlight some of the additional insights to be gained by calculating an individual's social

666 centrality across all interaction layers to fully understand their social role and influence.

667 Natal philopatry (remaining in the home range and/or social group in which you were born)

668 gives kin the opportunity to cooperate or preferentially interact (Wrangham, 1980; Stacey \&

669 Koenig, 1990; Emlen, 1991). Female rhesus macaques are philopatric and show a clear

670 preference for interacting with close relatives (Gouzoules \& Gouzoules, 1987; Bernstein, Judge

671 \& Ruehlmann, 1993). In fact, female kin bias contributes to key features of macaque social

672 structure, such as females' inheritance of dominance rank (due to agonistic support from

673 mothers, grandmothers, and sisters (Sade, 1969)). Consistent with the importance of kinship, we

674 found that females from large families $(11+$ members $)$ had higher consensus ranks than females

675 from medium-sized families (6-10 members). Females from larger families have more kin

676 partners with whom to interact, making it easier for them to be well-connected in grooming or

677 huddling networks. Indeed, the single-layer analyses suggest that the impact of matriline size on

678 centrality is likely through its impact on affiliative interactions because matriline size was a

679 predictor of grooming layer centrality, but not aggression or status layer centrality. However, it

680 was surprising that females from the smallest families (1-5 members) were just as central as

681 females from the largest families. We suspect this nonlinear relationship between family size and 682 multiplex centrality occurs because forming social bonds with non-kin may be a second strategy 
683 for being well-connected for females from small families. Female macaques can also form 684 critical social bonds with non-kin (Datta, 1986; Chapais, Girard \& Primi, 1991), and perhaps 685 females from small families form more social ties with non-family members because they have 686 insufficient numbers of family to meet their social needs. Thus, a multiplex approach revealed 687 new information regarding a non-linear relationship between centrality and family size.

688 Finally, we found that rearing history impacted multiplex centrality - nursery-reared (NR) 689 animals had lower consensus ranks than mother-reared (MR) animals. This is significant because 690 few studies have examined the impact of NR on social behavior of adults living in social groups 691 and results have been mixed. Some studies have found that NR adults are lower ranked than their 692 MR peers when housed together in groups (Bastian et al., 2003; Dettmer et al., 2017), and others 693 report no rearing related difference in adults' social behavior (Bauer \& Baker, 2016). NR is well

694 known to cause a number of physiological and behavioral deficits, and these effects have been 695 most consistently shown for young NR animals. NR animals up to 3 years of age exhibit more 696 aggression, less reciprocal social interaction, and an inability to use a social partner to buffer their response to a stressor (Winslow et al., 2003) likely due to early alterations in neural and endocrine systems (Clarke, 1993; Sánchez et al., 1998; Capitanio et al., 2006). In this study, we were unable to detect evidence of altered social behavior in NR animals in the single layer analyses but did detect such differences in the multiplex network. These findings offer further evidence that NR can impact adult social behavior (Bastian et al., 2003; Dettmer et al., 2017), and suggest that the social consequences of nursery rearing are complex and may be difficult to detect by examining a single facet of social life. 
717 Oates-O'Brien et al., 2010; Beisner et al., 2011a; Wooddell et al., 2016). Identifying socially central, and perhaps influential, individuals can guide management decisions to prevent social instability. Consensus ranks may also prove useful for understanding whether population social structure and animals' typical social roles may differ under different environmental conditions ecotourism can significantly impact animal behavior (Clarke, Collins \& Zucker, 2002; Lusseau

\section{Conclusion} greater insight into an individual's role in society compared to standard analytical approaches.

727 Current state-of-the-art methods for quantifying centrality in a multiplex do not adequately 
728 handle the complexity found in social networks, such as layers whose links differ in density,

729 function and directionality. Here we have shown that a new method that is designed to handle

730 these complexities across layers, consensus ranking (Pósfai et al., 2019), appropriately identified

731 which types of individuals tend to be central in a socially complex nonhuman primate (e.g., high-

732 ranking males with high certainty of rank; females from large families) and further highlighted

733 some patterns that might have otherwise gone undetected (i.e., females from the smallest families

734 were as central as those from the largest; NR individuals were less central than MR individuals).

\section{Acknowledgements}

736 We thank our dedicated behavioral data collection team including A. Barnard, T. Boussina, E.

737 Cano, J. Greco, M. Jackson, A. Maness, A. Nathman, A. Vitale, and S. Winkler. We thank Kelly

738 Finn for helpful discussions about multilayer networks. The content is solely the responsibility of

739 the authors and does not necessarily represent the official views of the National Institutes of

740 Health.

741 References

742 Akinyi MY, Tung J, Jeneby M, Patel NB, Altmann J, Alberts SC. 2013. Role of grooming in reducing tick load in wild baboons (Papio cynocephalus). Animal Behaviour 85:559-568. DOI: http://dx.doi.org/10.1016/j.anbehav.2012.12.012.

Allen J, Weinrich M, Hoppitt W, Rendell L. 2013. Network-Based Diffusion Analysis Reveals Cultural Transmission of Lobtail Feeding in Humpback Whales. Science 340:485-488. DOI: 10.1126/science.1231976.

Aplin LM, Farine DR, Morand-Ferron J, Sheldon BC. 2012. Social networks predict patch discovery in a wild population of songbirds. Proceedings of the Royal Society of London B: Biological Sciences 279:4199-4205. DOI: 10.1098/rspb.2012.1591. 
751 Arrow KJ. 2012. Social choice and individual values. Yale University Press.

752 Balasubramaniam KN, Beisner BA, Berman CM, De Marco A, Duboscq J, Koirala S, Majolo B, Maclntosh

753

754

755

756

757

758

759

760

761

762

763

764

765

766

767

768

769

770

771

772

773

AJ, McFarland R, Molesti S, Ogawa H, Petit O, Schino G, Sosa S, Sueur C, Thierry B, de Waal FBM, McCowan B. 2018. The influence of phylogeny, social style, and sociodemographic factors on macaque social network structure. American Journal of Primatology 80. DOI: 10.1002/ajp.22727.

Balasubramaniam K, Beisner B, Hubbard J, Vandeleest J, Atwill ER, McCowan B. 2019. Affiliation and Disease Risk: Social Networks Mediate Microbial Transmission among Rhesus Macaques. Animal Behaviour 151:131-143.

Balasubramaniam K, Beisner B, Vandeleest J, Atwill ER, McCowan B. 2016. Social buffering and contact transmission: network connections have beneficial and detrimental effects on Shigella infection risk among captive rhesus macaques. Peer J 4:e2630.

Barrett LF, Henzi SP, Lusseau D. 2012. Taking sociality seriously: the structure of multi-dimensional social networks as a source of information for individuals. Philosophical Transactions of the Royal Society of London B Biological Sciences 367:2108-2118.

Bastian ML, Sponberg AC, Sponberg AC, Suomi SJ, Higley JD. 2003. Long-term effects of infant rearing condition on the acquisition of dominance rank in juvenile and adult rhesus macaques (Macaca mulatta). Developmental Psychobiology 42:44-51. DOI: 10.1002/dev.10091.

Bauer S, Baker KC. 2016. Persistent effects of peer rearing on abnormal and species-appropriate activities but not social behavior in group-housed rhesus macaques (Macaca mulatta). Comparative Medicine 66:129-136.

Beisner BA, Hannibal DL, Finn KR, Fushing H, McCowan B. 2016. Social power, conflict policing, and the role of subordination signals in rhesus macaque society. American Journal Of Physical Anthropology 160:102-112.

Peer) reviewing PDF | (2019:06:38664:2:0:NEW 4 Feb 2020) 
774 Beisner BA, Jackson ME, Cameron A, McCowan B. 2011a. Detecting instability in animal social networks:

775 genetic fragmentation is associated with social instability in rhesus macaques. PLoS ONE

$776 \quad 6: e 16365$.

777 Beisner BA, Jackson ME, Cameron A, McCowan B. 2011b. Effects of natal male alliances on aggression

778 and power dynamics in rhesus macaques. American Journal of Primatology 73:790-801.

779 Beisner BA, Jackson ME, Cameron A, McCowan B. 2012. Sex ratio, conflict dynamics and wounding in

780 rhesus macaques (Macaca mulatta). Applied Animal Behaviour Science 137:137-147.

781

782

783

784

785

786

787

788

789

790

791

792

793

794

795

796
Beisner BA, Jin J, Fushing H, McCowan B. 2015. Detection of social group instability among captive rhesus macaques using joint network modeling. Current Zoology 61:70-84.

Beisner BA, McCowan B. 2013. Policing in nonhuman primates: partial interventions serve a prosocial conflict management function in rhesus macaques. PLoS ONE 8:e77369.

Berard J. 1999. A four-year study of the association between male dominance rank, residency status, and reproductive activity in rhesus macaques (Macaca mulatta). Primates 40:159-175.

Bernstein IS, Judge PG, Ruehlmann TE. 1993. Kinship, association, and social relationships in rhesus monkeys (Macaca mulatta). American Journal of Primatology 31:41-53. DOI: 10.1002/ajp.1350310105.

Bernstein I, Sharpe LG. 1966. Social roles in a rhesus monkey group. Behaviour 26:91-104.

Bianconi G. 2018. Multilayer Networks: Structure and Function. Oxford: Oxford University Press.

Bonacich P. 2007. Some unique properties of eigenvector centrality. Social Networks 29:555-564. DOI: 10.1016/j.socnet.2007.04.002.

de Borda JC. 1781. Mémoire sur les élections au scrutin. Bradbury JW, Vehrencamp SL. 2014. Complexity and behavioral ecology. Behavioral Ecology 25:435442. DOI: 10.1093/beheco/aru014.

Peer] reviewing PDF | (2019:06:38664:2:0:NEW 4 Feb 2020) 
797 Brent LN, Franks DW, Foster EA, Balcomb KC, Cant MA, Croft DP. 2015. Ecological knowledge, 798 leadership, and the evolution of menopause in killer whales. Current biology: CB 25:746-750. DOI: 10.1016/j.cub.2015.01.037.

800

801

802

803

804

805

806

807

808

809

810

811

812

813

814

815

816

817

818

819

Brent LJN, Heilbronner SR, Horvath JE, Gonzalez-Martinez J, Ruiz-Lambides A, Robinson AG, Skene JHP, Platt ML. 2013. Genetic origins of social networks in rhesus macaques. Scientific Reports 3:1042. DOI: $10.1038 /$ srep01042.

Burnham KP, Anderson DR. 2002. Model Selection and Multimodel Inference: A Practical InformationTheoretic Approach. New York: Springer-Verlag.

Burnham KP, Anderson DR, Huyvaert KP. 2011. AIC model selection and multimodel inference in behavioral ecology: some background,observations, and comparisons. Behavioral Ecology and Sociobiology 65:23-35.

Cameron EZ, Setsaas TH, Linklater WL. 2009. Social bonds between unrelated females increasereproductive success in feral horses. Proceedings of the National Academy of Science 106:13850-13853.

Capitanio JP, Mason WA, Mendoza SP, DelRossos L, Roberts JA. 2006. Nursery rearing and biobehavioral organization. In: Sackett GP, Ruppenthal GC, Elias K eds. Nursery Rearing of Nonhuman Primates in the 21st Century. New York: Springer, 191-214.

Chan S, Fushing H, Beisner BA, McCowan B. 2013. Joint modeling of multiple social networks to elucidate primate social dynamics: I. maximum entropy principle and network-based interactions. PLOS ONE 8:e51903.

Chapais B, Girard M, Primi G. 1991. Non-kin alliances, and the stability of matrilineal dominance relations in Japanese macaques. Animal Behaviour 41:481-491. DOI: 10.1016/S00033472(05)80851-6. 
820 Clarke AS. 1993. Social rearing effects on HPA axis activity over early development and in response to

821 stress in rhesus monkeys. Developmental Psychobiology 26:433-446. DOI:

822 10.1002/dev.420260802.

823

824

825

826

828

829

830

831

832

833

834

835

836

837

838

839

840

841

842

843

Clarke M, Collins D, Zucker E. 2002. Responses to Deforestation in a Group of Mantled Howlers (Alouatta palliata) in Costa Rica. International Journal of Primatology 23:365-381. DOI: 10.1023/A:1013839713223.

Croft DP, Madden JR, Franks DW, James R. 2011. Hypothesis testing in animal social networks. Trends in Ecology \& Evolution 26:502-507. DOI: 10.1016/j.tree.2011.05.012.

Datta SB. 1986. The role of alliances in the acquisition of rank. In: Else JG, Lee PC eds. Primate Ontogeny, Cognition, and Social Behaviour. New York: Cambridge University Prress, 219-225.

De Domenico M, Porter MA, Arenas A. 2015. MuxViz: a tool for multilayer analysis and visualization of networks. Journal of Complex Networks 3:159-176. DOI: 10.1093/comnet/cnu038.

De Domenico M, Solé-Ribalta A, Cozzo E, Kivelä M, Moreno Y, Porter MA, Gómez S, Arenas A. 2013. Mathematical Formulation of Multilayer Networks. Physical Review X 3:041022. DOI: 10.1103/PhysRevX.3.041022.

De Domenico M, Solé-Ribalta A, Omodei E, Gómez S, Arenas A. 2015. Ranking in interconnected multilayer networks reveals versatile nodes. Nature Communications 6:6868. DOI: 10.1038/ncomms7868 https://www.nature.com/articles/ncomms7868\#supplementaryinformation.

Defays D. 1977. An efficient algorithm for a complete link method. The Computer Journal 20:364-366. DOI: $10.1093 /$ comjnl/20.4.364.

Dettmer AM, Wooddell L, Rosenberg KL, Kaburu SSK, Novak MA, Meyer JS, Suomi SJ. 2017. Associations between early life experience, chronic HPA axis activity, and adult social rank in rhesus monkeys. Social Neuroscience 12:92-101. DOI: 10.1080/17470919.2016.1176952. 
844 Drewe JA. 2010. Who infects whom? Social networks and tuberculosis transmission in wild meerkats.

845

846

847

848

849

850

851

852

853

854

855

856

857

858

859

860

861

862

863

864

865

866

867 Proc Biol Sci 277:633-42. DOI: 10.1098/rspb.2009.1775.

Drickamer LC, Vessey SH. 1973. Group changing in free-ranging male rhesus monkeys. Primates 14:359368.

Dwork C, Kumar R, Naor M, Sivakumar D. 2001. Rank Aggregation Methods for the Web. In: Proceedings of the 10th International Conference on World Wide Web. WWW '01. New York, NY, USA: ACM, 613-622. DOI: 10.1145/371920.372165.

Ehardt CL, Bernstein I. 1986. Matrilineal overthrows in rhesus monkey groups. International Journal of Primatology 7:157-181.

Emlen ST. 1991. Evolution of cooperative breeding inbirds and mammals. In: Behavioural Ecology: An Evolutionary Approach (Krebs, J. R. \& Davies, N. B., eds). Oxford: Blackwell, 301-337.

Everitt B, Landau S, Leese M, Stahl D. 2011. Cluster Analysis, Fifth Edition. John Wiley \& Sons, Inc.

Farine DR. 2017. A guide to null models for animal social network analysis. Methods in Ecology and Evolution 8:1309-1320. DOI: 10.1111/2041-210X.12772.

Farine DR, Whitehead H. 2015. Constructing, conducting and interpreting animal social network analysis. Journal of Animal Ecology 84:1144-1163. DOI: 10.1111/1365-2656.12418.

Finn KR, Silk MJ, Porter MA, Pinter-Wollman N. 2019. The use of multilayer network analysis in animal behaviour. Animal Behaviour 149:7-22. DOI: 10.1016/j.anbehav.2018.12.016.

Fisher DN, Pruitt JN. 2019. Insights from the study of complex systems for the ecology and evolution of animal populations. Current Zoology. DOI: 10.1093/cz/zoz016.

Flack JC, Girvan M, de Waal FBM, Krakauer DC. 2006. Policing stabilizes construction of social niches in primates. Nature 439:426-429.

Flack JC, Krakauer DC. 2006. Encoding power in communication networks. The American Naturalist 168:E87-E102. 
868 Flack JC, Krakauer DC, de Waal FBM. 2005. Robustness mechanisms in primate societies: a perturbation 869 study. Proceedings of the Royal Society Biological Sciences Series B 272:1091-1099.

870 Flack JC, de Waal FBM, Krakauer DC. 2005. Social structure, robustness, and policing cost in a cognitively 871 sophisticated species. The American Naturalist 165:E000.

872 Fournier DA, Skaug HJ, Ancheta J, lanelli J, Magnusson A, Maunder M, Nielsen A, Sibert J. 2012. AD

$873 \quad$ Model Builder: using automatic differentiation for statistical inference of highly parameterized complex nonlinear models. Optimization Methods and Software 27:233-249.

Fujii K, Jin J, Shev A, Beisner BA, McCowan B, Fushing H. 2015. Perc: Using Percolation and Conductance to find information flow certainty in direct network.

Fushing H, Chen C. 2014. Data mechanics and coupling geometry on binary bipartite networks. PLoS ONE 9:e106154.

Fushing H, McAssey M, Beisner BA, McCowan B. 2011. Ranking network of a captive rhesus macaque 880 society: a sophisticated corporative kingdom. PLOS ONE 6:e17817.

881

882 883 884
Gouzoules S, Gouzoules H. 1987. Kinship. In: Primate Societies (Ed. by B. B. Smuts, D. L. Cheney, R. M. Seyfarth, R. W. Wrangham\& T. T. Struhsaker). Chicago: University of Chicago Press, 299-305.

Griffin RH, Nunn CL. 2012. Community structure and the spread of infectious disease in primate social networks. Evolutionary Ecology 26:779-800. DOI: 10.1007/s10682-011-9526-2.

Guan J, Fushing H. 2018. Coupling Geometry on Binary Bipartite Networks: Hypotheses Testing on Pattern Geometry and Nestedness. Frontiers in Applied Mathematics and Statistics 4. DOI: 10.3389/fams.2018.00038.

Halu A, Mondragón RJ, Panzarasa P, Bianconi G. 2013. Multiplex PageRank. PLoS ONE 8:e78293. DOI: 10.1371/journal.pone.0078293.

Hamilton WD. 1964. The genetical evolution of social behavior. I and II. Journal of Theoretical Biology 7:1-52. 
892 Hawkes K, O’Connell JF, Blurton Jones NG. 1997. Hadza women's time allocation, offspring provisioning, 893 and the evolution of long postmenopausal life spans. Current Anthropology 38:551-577. D0I:

894 $10.1086 / 204646$.

895

896

897

898

899

900

901

902

903

904

905

906

907

908

909

910

911

912

913

914

915
Hinde RA. 1976. Interactions, relationships, and social structure. Man 11:1-17.

Ilany A, Booms AS, Holekamp KE. 2015. Topological effects of network structure on long-term social network dynamics in a wild mammal. Ecology Letters 18:687-695. DOI: 10.1111/ele.12447.

Jack KM, Fedigan LM. 2018. Alpha Male Capuchins (Cebus capucinus imitator) as Keystone Individuals. In: Kalbitzer U, Jack KM eds. Primate Life Histories, Sex Roles, and Adaptability: Essays in Honour of Linda M. Fedigan. Developments in Primatology: Progress and Prospects. Cham: Springer International Publishing, 91-115. DOI: 10.1007/978-3-319-98285-4_6.

Jackson ME, Hannibal DL, Beisner BA, McCowan B. 2012. Matrilineal relatedness influences the efficacy of policing by alpha male rhesus macaques(Macaca mulatta). American Journal of Primatology $74: 74$.

Kaburu SSK, Marty PR, Beisner B, Balasubramaniam KN, Bliss-Moreau E, Kaur K, Mohan L, McCowan B. 2019. Rates of human-macaque interactions affect grooming behavior among urban-dwelling rhesus macaques (Macaca mulatta). American Journal of Physical Anthropology 168:92-103. DOI: 10.1002/ajpa.23722.

Kachel AF, Premo LS, Hublin JJ. 2011. Grandmothering and natural selection. Proceedings of the Royal Society B: Biological Sciences 278:384-391. DOI: 10.1098/rspb.2010.1247.

Kivelä M, Arenas A, Barthelemy M, Gleeson JP, Moreno Y, Porter MA. 2014. Multilayer networks. Journal of Complex Networks 2:203-271. DOI: 10.1093/comnet/cnu016.

Koford CB. 1963. Rank of mothers and sons in bands of rhesus monkeys. Science 141:356-357.

Lehmann J, Korstjens AH, Dunbar RIM. 2007. Group size, grooming and social cohesion in primates. Animal Behaviour 74:1617-1629.

Peer] reviewing PDF | (2019:06:38664:2:0:NEW 4 Feb 2020) 
916 Lusseau D. 2003. Emergent properties of a dolphin social network. Proceedings of the Royal Society $B$

917

918

919

920

921

922

923

924

925

926

927

928

929

930

931

932

933

934

935

936

937

938 270:S186-S188.

Lusseau D, Higham JES. 2004. Managing the impacts of dolphin-based tourism through the definition of critical habitats: the case of bottlenose dolphins (Tursiops spp.) in Doubtful Sound, New Zealand. Tourism Management 25:657-667. DOI: http://dx.doi.org/10.1016/j.tourman.2003.08.012.

Lusseau D, Newman MEJ. 2004. Identifying the role that animals play in their social networks. Proceedings of the Royal Society B: Biological Sciences 271:S477-S481.

Marty PR, Beisner B, Kaburu SSK, Balasubramaniam K, Bliss-Moreau E, Ruppert N, Mohd Sah SA, Ismail A, Arlet ME, Atwill ER, McCowan B. 2019. Time constraints imposed by anthropogenic environments alter social behaviour in longtailed macaques. Animal Behaviour 150:157-165. DOI: 10.1016/j.anbehav.2019.02.010.

McComb Karen, Shannon Graeme, Durant Sarah M., Sayialel Katito, Slotow Rob, Poole Joyce, Moss Cynthia. 2011. Leadership in elephants: the adaptive value of age. Proceedings of the Royal Society B: Biological Sciences 278:3270-3276. DOI: 10.1098/rspb.2011.0168.

McComb K, Moss C, Durant SM, Baker L, Sayialel S. 2001. Matriarchs as repositories of social knowledge in African elephants. Science (New York, N.Y.) 292:491-494. DOI: 10.1126/science.1057895.

McCowan B, Beisner BA, Capitanio JP, Jackson ME, Cameron A, Seil S, Atwill ER, Fushing H. 2011. Network stability is a balancing act of personality, power, and conflict dynamics in rhesus macaque societies. PLOS ONE 6:e22350.

Modlmeier AP, Keiser CN, Watters JV, Sih A, Pruitt JN. 2014. The keystone individual concept: an ecological and evolutionary overview. Animal Behaviour 89:53-62. DOI: http://dx.doi.org/10.1016/j.anbehav.2013.12.020.

Müllner D. 2011. Modern hierarchical, agglomerative clustering algorithms. arXiv:1109.2378 [cs, stat]. 
939 Oates-O’Brien RS, Farver TB, Anderson-Vicino KC, McCowan B, Lerche NW. 2010. Predictors of

940 matrilineal overthrows in large captive breeding groups of rhesus macaques (Macaca mulatta).

941 Journal of the American Association for Laboratory Animal Science 49:196-201.

942 Pasquaretta C, Leve M, Claidiere N, van de Waal E, Whiten A, Maclntosh AJJ, Pele M, Bergstrom ML, Borgeaud C, Brosnan SF, Crofoot MC, Fedigan LM, Fichtel C, Hopper LM, Mareno MC, Petit O, Schnoell AV, di Sorrentino EP, Thierry B, Tiddi B, Sueur C. 2014. Social networks in primates: smart and tolerant species have more efficient networks. Scientific Reports 4. DOI:

946

947

948 $10.1038 /$ srep07600

949 http://www.nature.com/srep/2014/141223/srep07600/abs/srep07600.html\#supplementaryinformation.

Pinter-Wollman N, Wollman R, Guetz A, Holmes S, Gordon D. 2011. The effect of individual variation on the structure and function of interaction networks in harvester ants. Journal of the Royal Society Interface 8:1562-1573.

Pósfai M, Braun N, Beisner B, McCowan B, D’Souza R. 2019. Consensus ranking for multi-objective interventions in multiplex networks. New Journal of Physics 21:055001.

Ramos-Fernández G, Boyer D, Aureli F, Vick LG. 2009. Association networks in spider monkeys (Ateles geoffroyi). Behavioral Ecology and Sociobiology 63:999-1013. DOI: 10.1007/s00265-009-0719-4.

von Rohr CR, Koski SE, Burkart JM, Caws C, Fraser ON, Ziltener A, van Schaik CP. 2012. Impartial thirdparty interventions in captive chimpanzees: a reflection of community concern. PLoS ONE

958 7:e32494.

Sade DS. 1969. An algorithm for dominance relations: Rules for adult females and sisters. American Journal Of Physical Anthropology 31:271.

Sade DS. 1972a. Sociometrics of Macaca mulatta I. Linkages and cliques in grooming matrices. Folia Primatologica 18:196-223. 
963 Sade DS. 1972b. A longitudinal study of social behavior of rhesus monkeys. In: Tuttle R ed. The

$964 \quad$ Functional and Evolutionary Biology of Primates. New York: Aldine Atherton, 378-398.

965 Sade DS, Altmann M, Loy J, Hausfater G. 1988. Sociometrics of Macaca mulatta: II. Decoupling Centrality

966 and Dominance in Rhesus Monkey Social Networks. American Journal Of Physical Anthropology

$967 \quad 77: 409-425$.

968 Sánchez MM, Hearn EF, Do D, Rilling JK, Herndon JG. 1998. Differential rearing affects corpus callosum

969 size and cognitive function of rhesus monkeys. Brain Research 812:38-49. DOI: 10.1016/S0006-

970 8993(98)00857-9.

971 Sapolsky RM. 1992. Cortisol concentrations and the social significance of rank instability among wild

972 baboons. Psychoneuroendocrinology 17:701-709.

973 Seyfarth RM. 1977. A model of social grooming among adult female monkeys. Journal of Theoretical $974 \quad$ Biology 65:671-698.

975 Silk JB, Beehner JC, Bergman TJ, Crockford C, Engh AL, Moscovice LR, Wittig RM, Seyfarth RM, Cheney

976 DL. 2009. The benefits of social capital: close social bonds among female baboons enhance

977 offspring survival. Proc Biol Sci 276:3099-104. DOI: 10.1098/rspb.2009.0681.

978 Silk JB, Beehner JC, Bergman TJ, Crockford C, Engh AL, Moscovice LR, Wittig RM, Seyfarth RM, Cheney

979 DL. 2010. Strong and consistent social bonds enhance the longevity of female baboons. Current

980 Biology 20:1359-61. DOI: 10.1016/j.cub.2010.05.067.

981 Silk MJ, Finn KR, Porter MA, Pinter-Wollman N. 2018. Can Multilayer Networks Advance Animal Behavior

982 Research? Trends in Ecology \& Evolution 33:376-378. DOI: 10.1016/j.tree.2018.03.008.

983 Smith-Aguilar SE, Aureli F, Busia L, Schaffner C, Ramos-Fernández G. 2018. Using multiplex networks to

984 capture the multidimensional nature of social structure. Primates. DOI: 10.1007/s10329-018-

$985 \quad$ 0686-3. 
986 Stacey PB, Koenig WD. 1990. Cooperative Breeding in Birds: Long-Term Studies of Ecology and

987 Behaviour. Cambridge: Cambridge University Press.

988 Stanton MA, Mann J. 2012. Early social networks predict survival in wild bottlenose dolphins. PloS One

989 7:e47508. DOI: 10.1371/journal.pone.0047508.

990 Sueur C, Petit O, De Marco A, Jacobs AT, Watanabe K, Thierry B. 2011. A comparative network analysis

991 of social style in macaques. Animal Behaviour 82:845-852. DOI:

992

http://dx.doi.org/10.1016/j.anbehav.2011.07.020.

993

994

995

996

997

998

999

1000

1001

1002

1003

1004

1005

1006

1007

1008

1009

Sugiyama Y. 1976. Life history of male Japanese monkeys. In: Rosenblatt JS ed. Advances in the Study of Behavior. New York: Academic Press, 255-284.

Sundaresan SR, Fischhoff IR, Dushoff J, Rubenstein DI. 2006. Network metrics reveal differences in social organization between two fission-fusion species, Grevy's zebra and onager. Oecologia 151:140149. DOI: $10.1007 / \mathrm{s} 00442-006-0553-6$.

Suomi SJ. 2006. Risk, Resilience, and Gene $\times$ Environment Interactions in Rhesus Monkeys. Annals of the New York Academy of Sciences 1094:52-62. DOI: 10.1196/annals.1376.006.

Thierry B. 2004. Social epigenesis. In: Thierry B, Singh M, Kaumanns W eds. Macaque Societies. Cambridge: Cambridge University Press, 267-290.

Tilford BL. 1982. Seasonal rank changes for adolescent and subadult natal males in a free-ranging group of rhesus monkeys. International Journal of Primatology 3:483-490.

Vandeleest JJ, Beisner BA, Hannibal DL, Nathman A, Capitanio J, Fushing H, McCowan B. 2016. Decoupling social status and status certainty effects on health in macaques: a network approach. Peer J 4:e2394.

VanderWaal KL, Atwill ER, Hooper S, Buckle K, McCowan B. 2013. Network structure and prevalence of Cryptosporidium in Belding's ground squirrels. Behavioral Ecology and Sociobiology 67:19511959. DOI: 10.1007/s00265-013-1602-x. 
1010 VanderWaal KL, Atwill ER, Isbell LA, McCowan B. 2014. Linking social and pathogen transmission

1011

1012

1013

1014

1015

1016

1017

1018

1019

1020

1021

1022

1023

1024

1025

1026

1027

1028

1029

1030

1031

networks using microbial genetics in giraffe (Giraffa camelopardalis). Journal of Animal Ecology 83:406-414. DOI: 10.1111/1365-2656.12137.

Vehrencamp SL. 1983. A model for the evolution of despotic versus egalitarian societies. Animal Behaviour 31:667-682. DOI: 10.1016/S0003-3472(83)80222-X.

West Eberhard MJ. 1975. The Evolution of Social Behavior by Kin Selection. The Quarterly Review of Biology 50:1-33. DOI: 10.1086/408298.

Wey T, Blumstein DT, Shen W, Jordán F. 2008. Social network analysis of animal behaviour: a promising tool for the study of sociality. Animal Behaviour 75:333-344. DOI:

10.1016/j.anbehav.2007.06.020.

Whitehead H. 2008. Analyzing Animal Socities: Quantitative Methods for Vertebrate Social Analysis. Chicago: University of Chicago Press.

Whitehead H, Dufault S. 1999a. Techniques for analyzing vertebrate social structure using identified individuals: review and recommendations. In: Advances in the Study of Behavior. San Diego: Academic Press, 33-74.

Whitehead H, Dufault S. 1999b. Techniques for analyzing vertebrate social structure using identified individuals: review and recommendations. In: Advances in the Study of Behavior. San Diego: Academic Press, 33-74.

Winslow JT, Noble PL, Lyons CK, Sterk SM, Insel TR. 2003. Rearing effects on cerebrospinal fluid oxytocin concentration and social buffering in rhesus monkeys. Neuropsychopharmacology: Official Publication of the American College of Neuropsychopharmacology 28:910-918. DOI: 10.1038/sj.npp.1300128. 
1032

1033

1034

1035

1036

1037

1038

1039

1040

1041

1042

1043

1044

1045

1046

1047

1048

1049

1050

1051

1052

1053

Wooddell LJ, Kaburu SSK, Rosenberg KL, Meyer JS, Suomi SJ, Dettmer AM. 2016. Matrilineal Behavioral and Physiological Changes following the Removal of a Non-Alpha Matriarch in Rhesus Macaques (Macaca mulatta). PLOS ONE 11:e0157108. DOI: 10.1371/journal.pone.0157108.

Wrangham R. 1980. An ecological model of female-bonded primate groups. Behaviour 75:262-300.

\section{Figure Legends.}

Figure 1. The method for assigning rank tiers is illustrated. Hierarchical clustering was performed on the centrality values for a given network layer. The hierarchical clustering tree shown in (a) maps onto the plot of centrality values ordered from largest to smallest shown in (b) such that all members of the same cluster are assigned the same rank tier (different rank tiers denoted by alternating colors green and purple in the bar graph in (b)). Plot (c) shows 1- $\mathrm{r}^{2}$ (the correlation between the original and tiered centralities) with respect to the number of tiers. The final number of rank tiers selected (i.e., the height at which the clustering tree is cut) is the first one which falls below the threshold line (where $99 \%$ of the variance is explained). Illustrated is the aggression layer for group B.

Figure 2. Spearman correlations for all pairs of network layers, based upon the centrality rankings of each layer, across all study groups. The lettered labels A-G correspond to group IDs.

Figure 3. Heatmap showing the block structure revealed by Data Mechanics and the associated hierarchical clustering trees on the columns (layers) and the rows (individuals) for group B. Row clusters group together individuals with similar centrality ranks across the 5 layers, and column clusters group together layers with similar values across all individuals. Darker colors in the heatmap represent larger values (i.e., low centrality ranks within each layer) and lighter colors represent smaller values (i.e., high centrality ranks within each layer). The grayscale bars on the 
$1054 \mathrm{y}$-axis indicate animals' dominance rank (left) and Borda rank (right). Lighter colors represent 1055 smaller values (i.e., high rank) and darker represents larger values.

1056 Figure 4. Predicted reversed Borda ranks for (A) females and (B) males, calculated at two levels 1057 of dominance certainty from the observed range of values: high dominance certainty 1058 (transformed DC $=0.1$ ) and low dominance certainty (transformed $\mathrm{DC}=0.3$ ). Predicted values 1059 are based upon Model 1 of reversed Borda ranks.

1060 Figure 5. Histograms of coefficients for each predictor generated from fitting Model 1 to the 1061 network randomizations. For each randomization $(n=1000)$, all the node labels in the original 1062 network (e.g., sex, age, rank) were shuffled; then the same model (reversed Borda rank 1063 rank*sex*DC + matriline size category*sex + rearing) was run for each randomized network. 1064 The vertical red line shows the value of the model coefficient for each predictor from the 1065 observed network data.

1066 Figure 6. Predicted reversed rank in the grooming layer relative to dominance rank (proportion 1067 of others outranked) and matriline size category. Predicted values are based upon Model 1 of 1068 grooming layer rank.

1069 Figure 7. Reversed Borda ranks (i.e., 1=low) plotted against dominance rank (proportion of 1070 others outranked) for all seven study groups. Red dots represent females; turquoise dots represent 1071 males. 


\section{Figure 1}

The method for assigning rank tiers is illustrated.

Hierarchical clustering was performed on the centrality values for a given network layer. The hierarchical clustering tree shown in (a) maps onto the plot of centrality values ordered from largest to smallest shown in (b) such that all members of the same cluster are assigned the same rank tier (different rank tiers denoted by alternating colors green and purple in the bar graph in (b)). Plot (c) shows 1- $r^{2}$ (the correlation between the original and tiered centralities) with respect to the number of tiers. The final number of rank tiers selected (i.e., the height at which the clustering tree is cut) is the first one which falls below the threshold line (where $99 \%$ of the variance is explained). Illustrated is the aggression layer for group B.

(a)

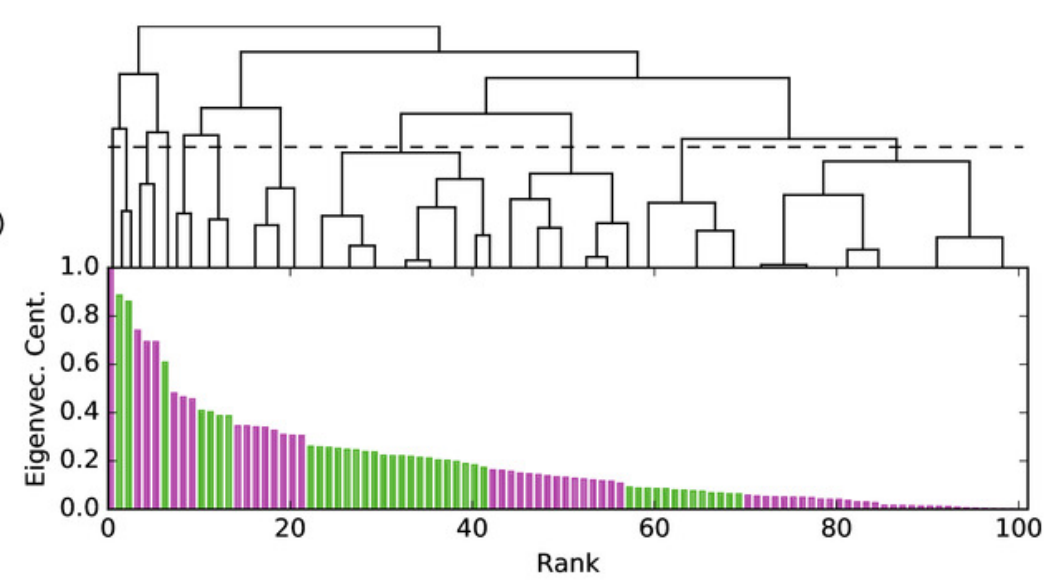

(c)

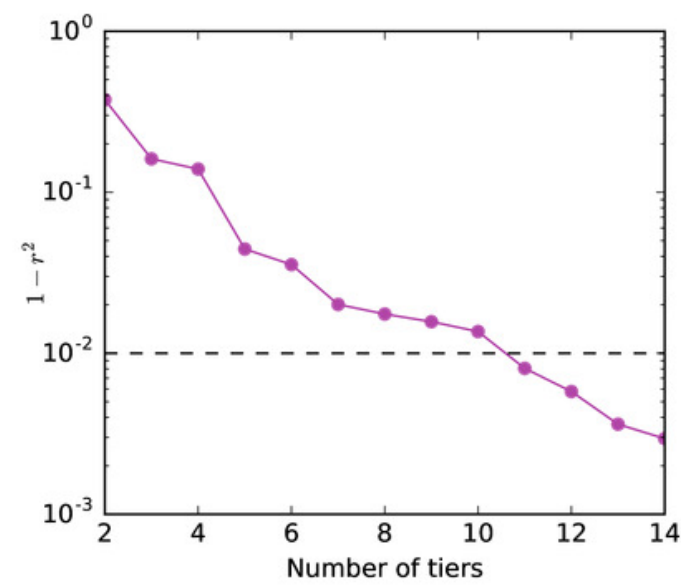


Figure 2

Heatmap of layer correlations for all groups

Spearman correlations were calculated for all pairs of network layers, using the centrality rankings of each layer, across all study groups. The lettered labels A-G correspond to group IDs. 

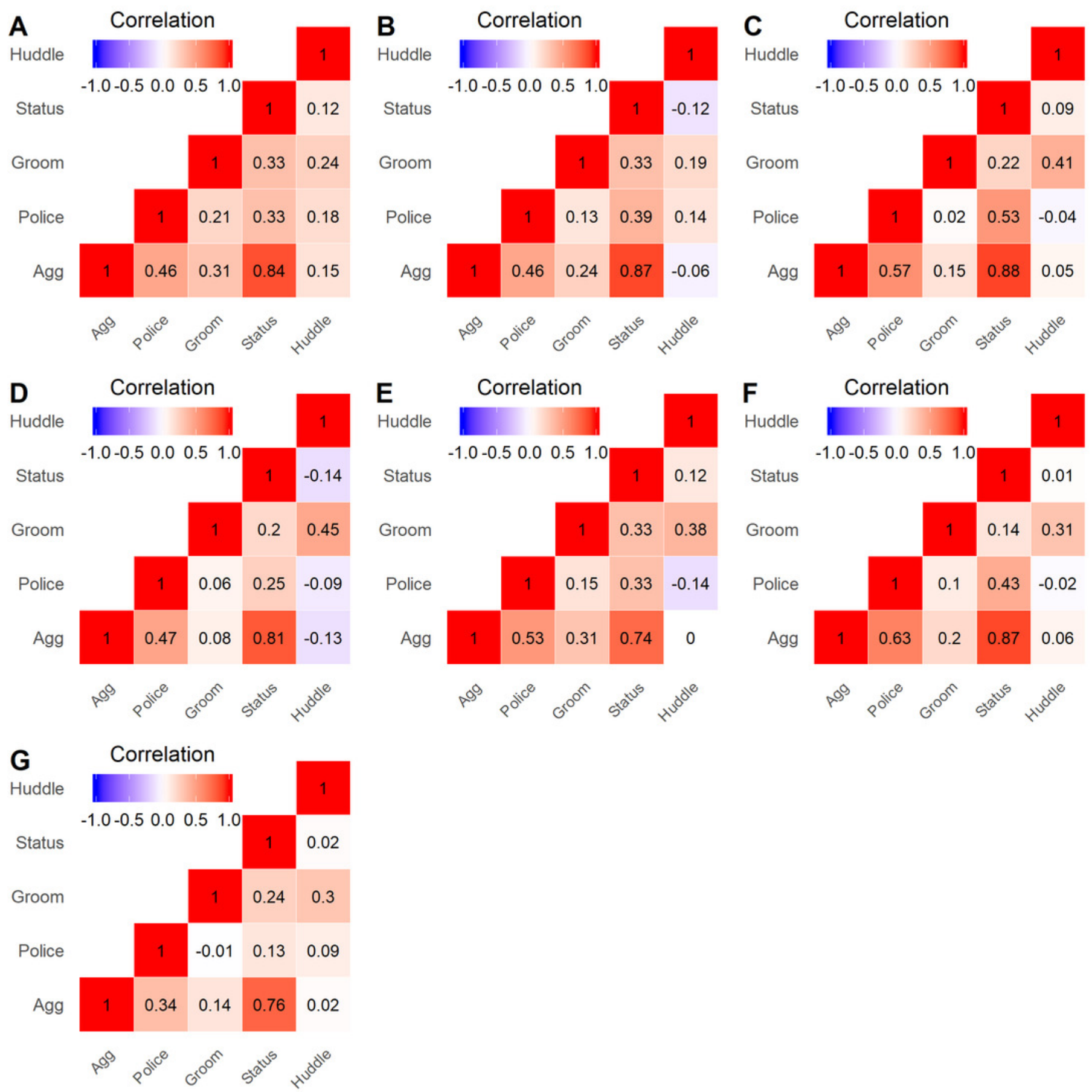


\section{Figure 3}

Data Mechanics heatmap

Heatmap showing the block structure revealed by Data Mechanics and the associated hierarchical clustering trees on the columns (layers) and the rows (individuals) for group B. Row clusters group together individuals with similar centrality ranks across the 5 layers, and column clusters group together layers with similar values across all individuals. Darker colors in the heatmap represent larger values (i.e., low centrality ranks within each layer) and lighter colors represent smaller values (i.e., high centrality ranks within each layer). The grayscale bars on the y-axis indicate animals' dominance rank (left) and Borda rank (right). Lighter colors represent smaller values (i.e., high rank) and darker represents larger values. 


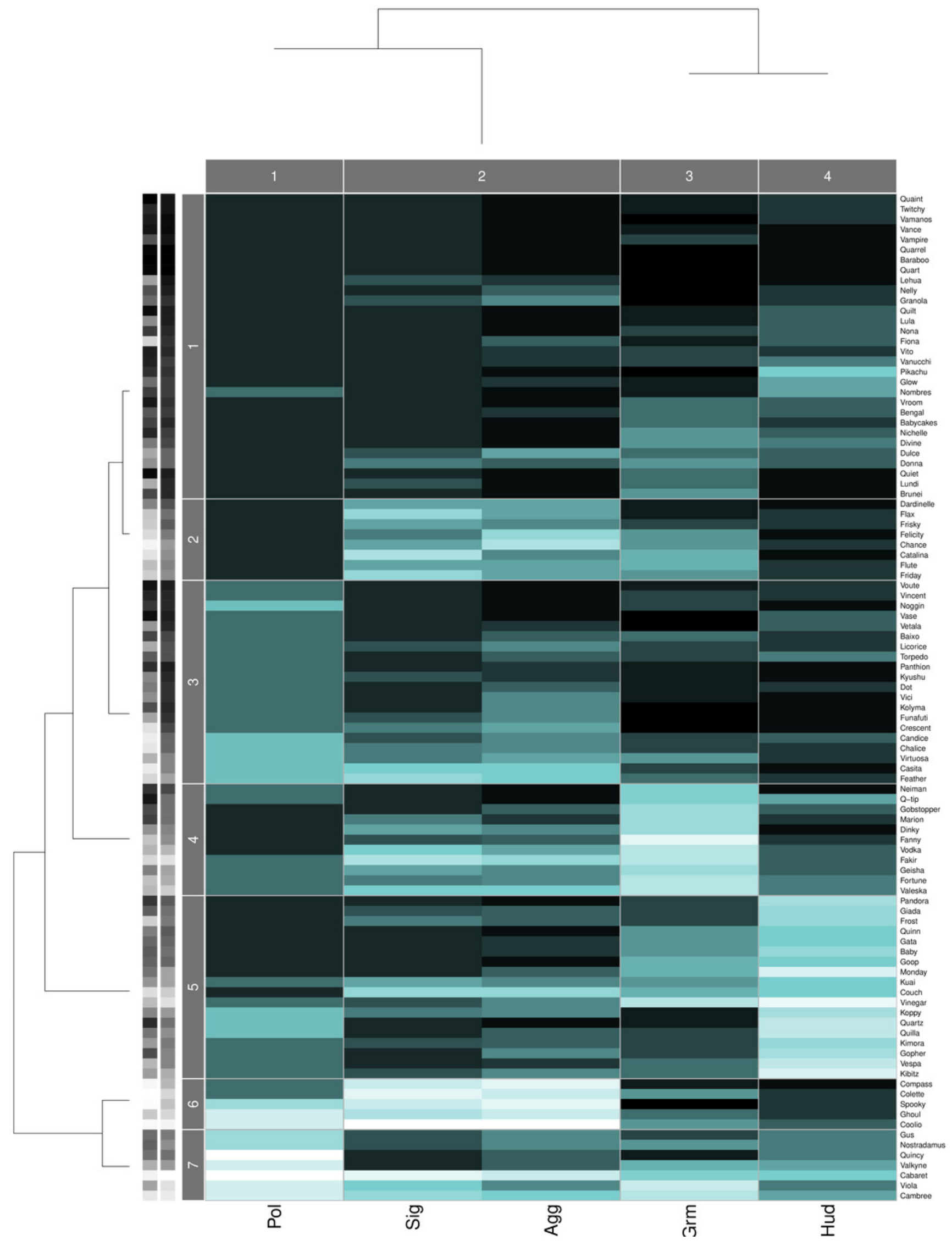




\section{Figure 4}

Model predicted values of reverse Borda ranks relative to rank, sex and dominance certainty, based upon Model 1.

Predicted reverse Borda ranks for (A) females and (B) males, calculated at two levels of dominance certainty from the observed range of values: high dominance certainty (transformed DC $=0.1$ ) and low dominance certainty (transformed DC $=0.3$ ). Predicted values are based upon Model 1 of reversed Borda ranks. 


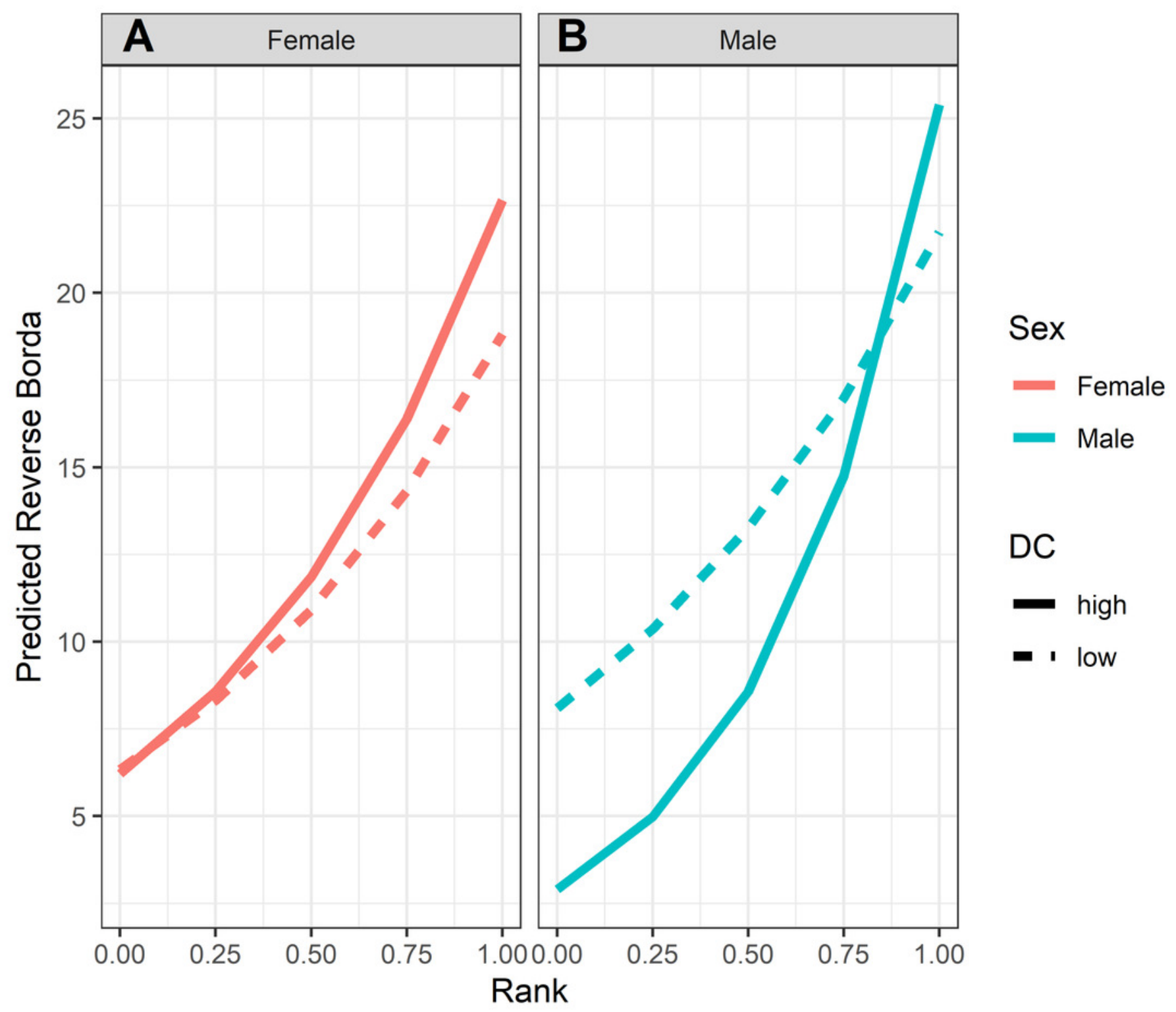




\section{Figure 5}

Histograms of model coefficients from network randomizations

Histograms of coefficients for each predictor generated from fitting Model 1 to the network randomizations. For each randomization $(n=1000)$, all the node labels in the original network (e.g., sex, age, rank) were shuffled; then the same model (reversed Borda rank rank*sex*DC + matriline size category*sex + rearing) was run for each randomized network. The vertical red line shows the value of the model coefficient for each predictor from the observed network data. 

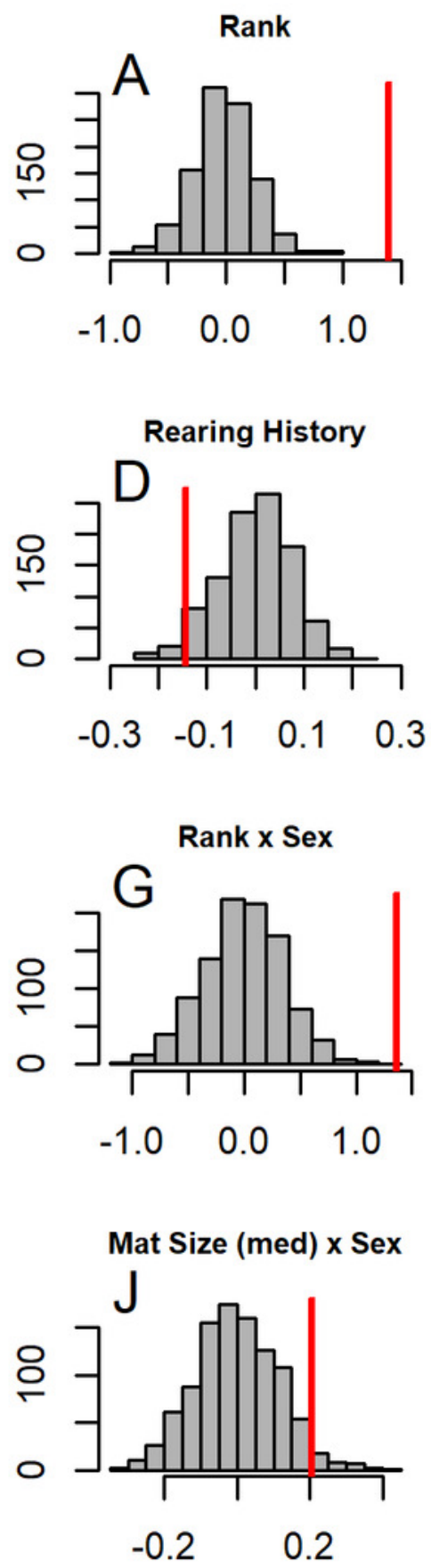
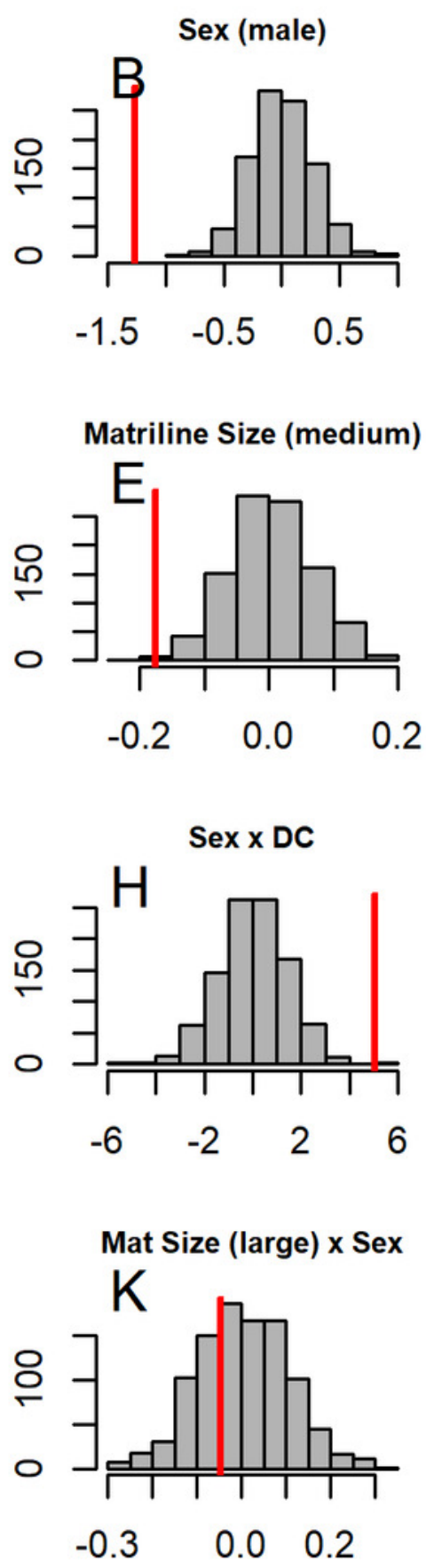
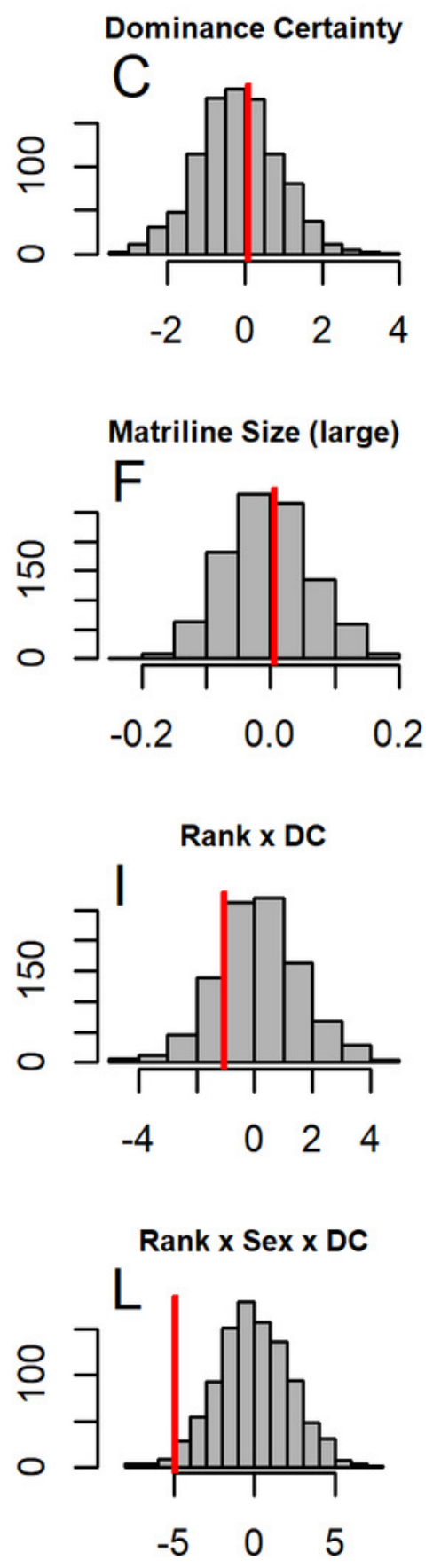
Figure 6

Model predicted values of reverse grooming layer ranks relative to dominance rank and matriline size

Predicted reversed rank in the grooming layer with respect to dominance rank (proportion of others outranked) and matriline size category. Predicted values are based upon Model 1 of grooming layer rank.

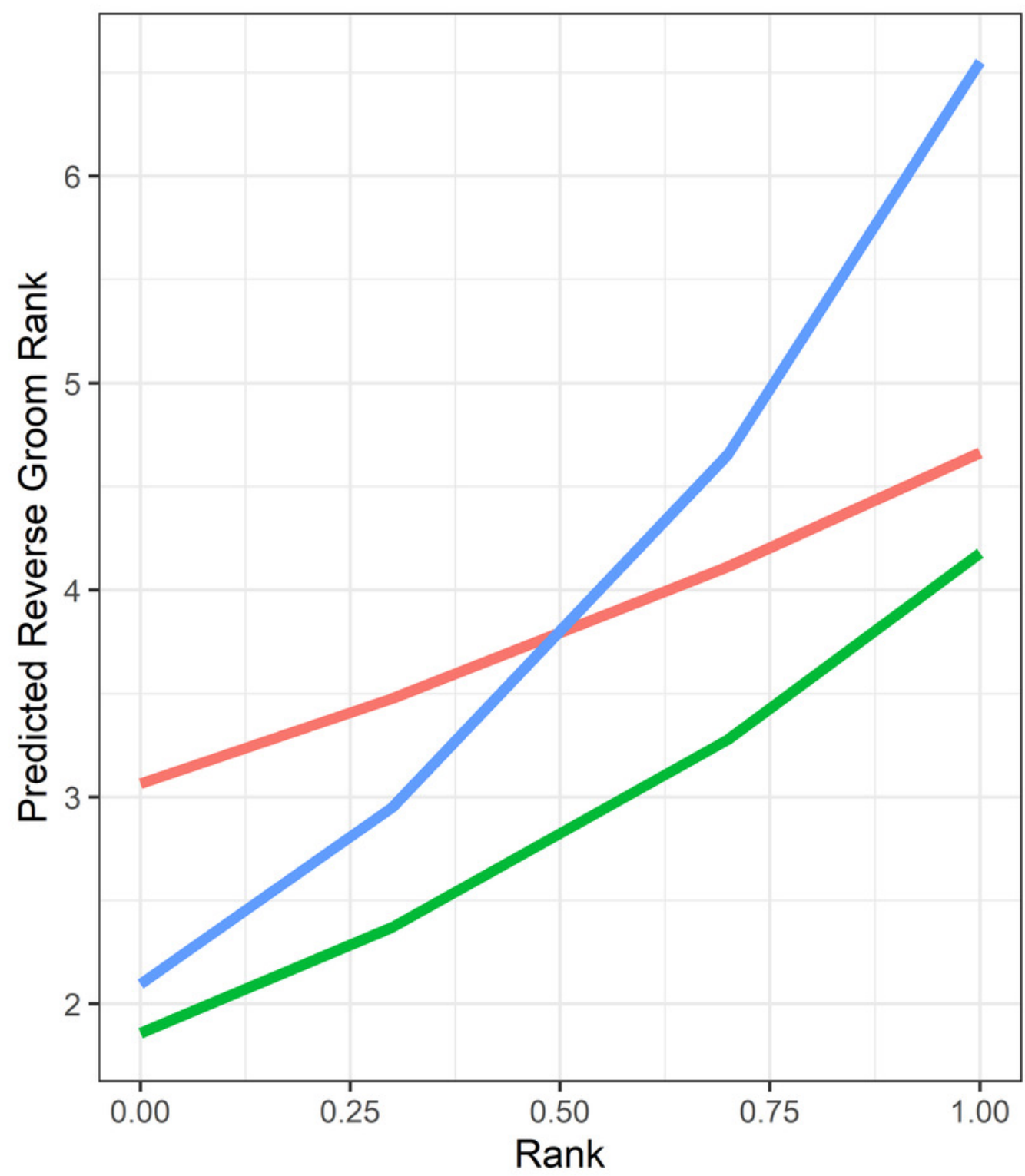

MatrilineSize

- large $(11+)$

medium (6-10)

- small (1-5) 
Figure 7

Raw data plots of reverse Borda ranks against dominance rank for all study groups

Reversed Borda ranks (i.e., $1=$ low) plotted against dominance rank (proportion of others outranked) for all seven study groups. Red dots represent females; turquoise dots represent males. 

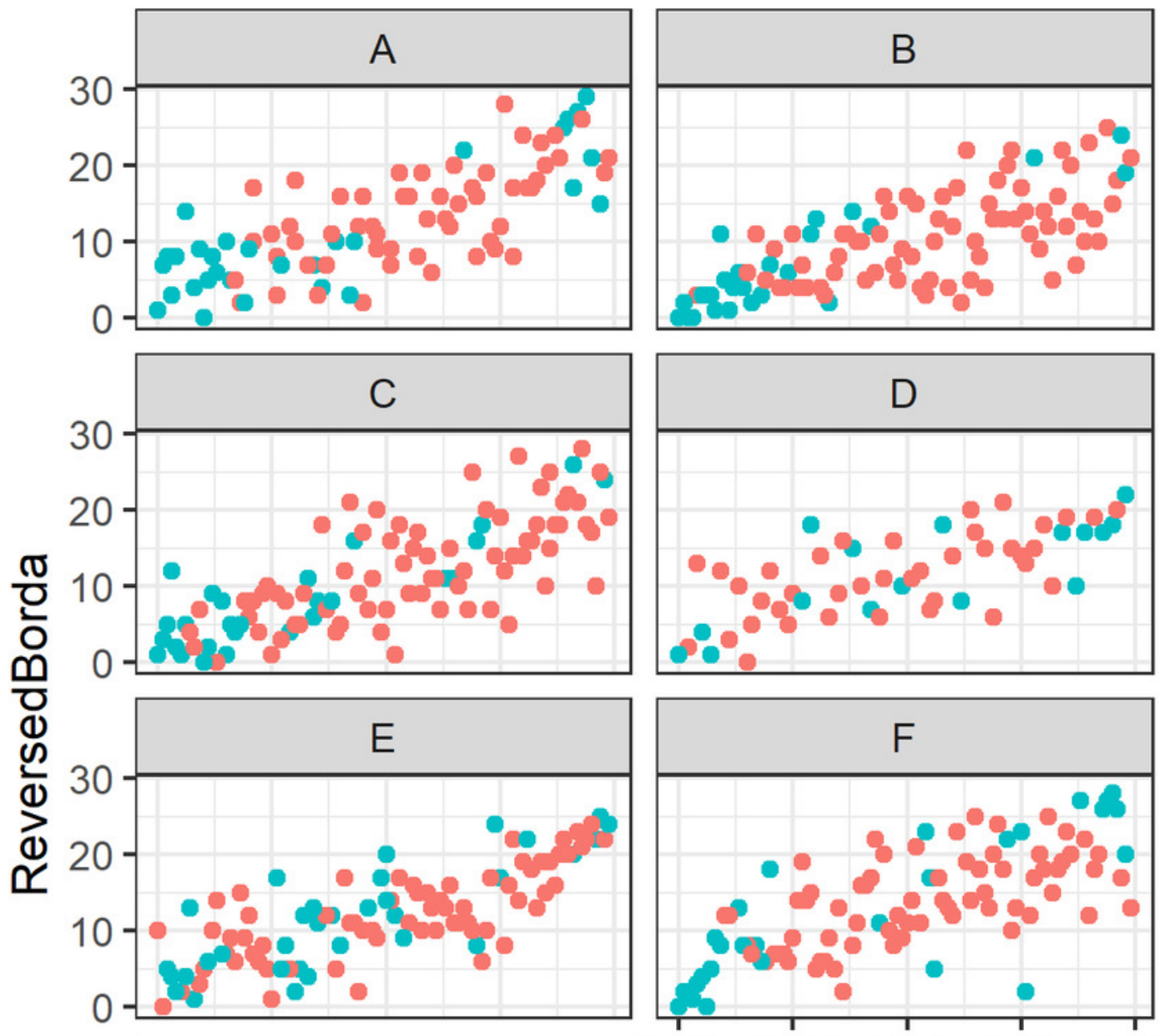

Sex

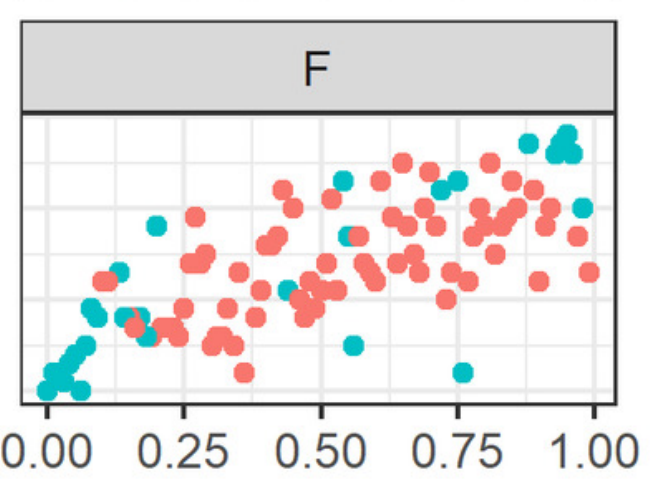

- Female

- Male

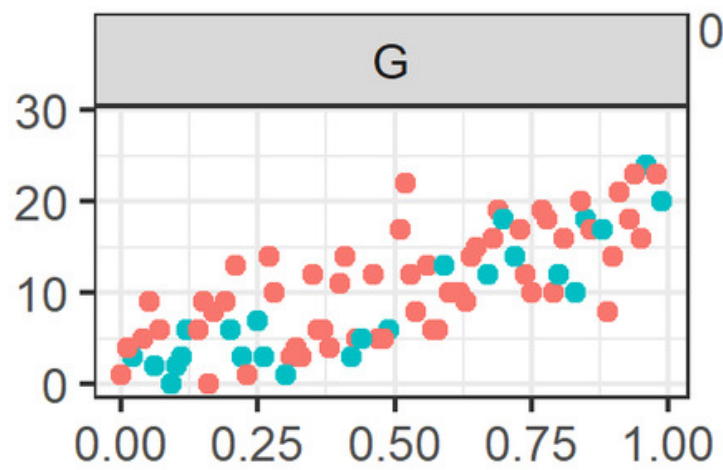

Rank (proportion others outranked) 
Table $\mathbf{1}$ (on next page)

Study group characteristics 
1 Table 1. Study group characteristics

\begin{tabular}{|l|l|l|l|l|l|l|}
\hline Group & $\begin{array}{l}\text { Adult group size } \\
\text { (males, females) }\end{array}$ & $\begin{array}{l}\text { Age range } \\
\text { yrs (mean) }\end{array}$ & Matrilines & $\begin{array}{l}\text { Matriline } \\
\text { Size }\end{array}$ & $\begin{array}{l}\text { Percent } \\
\text { Nursery- } \\
\text { reared }\end{array}$ & $\begin{array}{l}\text { Year } \\
\text { studied }\end{array}$ \\
\hline A & $87(30,57)$ & $3-19(7.2)$ & 26 & $1-17$ & $14.9 \%$ & 2012 \\
\hline B & $99(26,73)$ & $3-28(7.5)$ & 15 & $1-22$ & 0 & 2012 \\
\hline C & $101(27,74)$ & $3-29(8.0)$ & 15 & $1-20$ & 0 & 2013 \\
\hline D & $55(16,39)$ & $3-11(6.0)$ & 7 & $1-36$ & 0 & 2013 \\
\hline E & $101(34,67)$ & $3-11(5.9)$ & 37 & $1-15$ & $8.9 \%$ & 2014 \\
\hline F & $96(28,68)$ & $3-21(8.3)$ & 14 & $1-24$ & $5.2 \%$ & 2014 \\
\hline G & $81(24,57)$ & $3-21(8.2)$ & 30 & $1-17$ & $18.5 \%$ & 2016 \\
\hline
\end{tabular}

2 a Age range of adult subjects measured in years, starting with the youngest subjects at 3 years of 3 age

4 b Percent of group members that experienced maternal deprivation by being permanently 5 separated from their mother (with subsequent peer- or nursery-rearing) prior to reaching 12 6 months of age. 


\section{Table 2 (on next page)}

Network density (the proportion of all possible edges that are observed in the network) for all five network layers across all seven study groups 
1 Table 2. Network density (the proportion of all possible edges that are observed in the network)

2 for all five network layers across all seven study groups

\begin{tabular}{|l|l|l|l|l|l|}
\hline Group & Aggression & Status & Police & Groom & Huddle \\
\hline A & 0.271 & 0.085 & 0.021 & 0.259 & 0.190 \\
\hline B & 0.219 & 0.090 & 0.010 & 0.188 & 0.299 \\
\hline C & 0.261 & 0.086 & 0.015 & 0.235 & 0.244 \\
\hline D & 0.355 & 0.177 & 0.018 & 0.346 & 0.314 \\
\hline E & 0.243 & 0.086 & 0.012 & 0.237 & 0.316 \\
\hline F & 0.332 & 0.138 & 0.019 & 0.237 & 0.132 \\
\hline G & 0.182 & 0.120 & 0.010 & 0.212 & 0.211 \\
\hline
\end{tabular}

3 


\section{Table 3 (on next page)}

Parameter coefficients from the top two models of consensus rank compared against the distribution of model coefficients (Mean \pm SD) generated from 1000 network randomizations. Coefficients with $p \leq 0.10$ (based upon randomizations) are in bold and italics

${ }^{\mathrm{a}} \mathrm{DC}=$ dominance certainty, ranging from 0 (certain) to 0.5 (ambiguous)

${ }^{\mathrm{b}} \mathrm{MSC}=$ matriline size category $($ small $=1-5 ;$ medium $=6-10 ;$ large $=11+$ members $)$ 
1 Table 3. Parameter coefficients from the top two models of consensus rank compared against the 2 distribution of model coefficients (Mean \pm SD) generated from 1000 network randomizations. Coefficients 3 with $p \leq 0.10$ (based upon randomizations) are in bold and italics.

\begin{tabular}{|c|c|c|c|c|}
\hline & Model 1 & Model 1 & Model 2 & Model 2 \\
\hline & $\begin{array}{l}\text { GLMM } \\
\text { Coeff's }\end{array}$ & $\begin{array}{c}\text { Randomization } \\
\text { Coefficients } \\
\text { Mean } \pm \text { SD } \\
(p-v a l u e) \\
\end{array}$ & $\begin{array}{l}\text { GLMM } \\
\text { Coeff's }\end{array}$ & $\begin{array}{c}\text { Randomization } \\
\text { Coefficients } \\
\text { Mean } \pm \text { SD } \\
\text { (p-value) }\end{array}$ \\
\hline Intercept & 1.82 & $\begin{array}{c}2.44 \pm 0.20 \\
(0.006)\end{array}$ & 1.80 & $\begin{array}{c}2.45 \pm 0.21 \\
(0.008)\end{array}$ \\
\hline Sex [male] & -1.27 & $\begin{array}{c}0.0002 \pm 0.26 \\
(<0.001)\end{array}$ & -1.25 & $\begin{array}{c}-0.01 \pm 0.26 \\
(<0.001)\end{array}$ \\
\hline Rank & 1.39 & $\begin{array}{c}-0.02 \pm 0.25 \\
(<0.001)\end{array}$ & 1.43 & $\begin{array}{c}-0.03 \pm 0.26 \\
(<0.001)\end{array}$ \\
\hline $\mathrm{DC}^{\mathrm{a}}$ & 0.10 & $\begin{array}{c}-0.16 \pm 1.05 \\
(0.79)\end{array}$ & 0.18 & $\begin{array}{c}-0.19 \pm 1.08 \\
(0.72)\end{array}$ \\
\hline $\begin{array}{l}\text { Rearing } \\
\text { [nursery] }\end{array}$ & -0.14 & $\begin{array}{c}-0.001 \pm 0.08 \\
(0.07)\end{array}$ & -0.16 & $\begin{array}{c}-0.0006 \pm 0.07 \\
(0.04)\end{array}$ \\
\hline $\begin{array}{l}\operatorname{MSC}^{b}[6-10] \\
\text { vs. }[1-5]\end{array}$ & -0.18 & $\begin{array}{c}0.003 \pm 0.06 \\
(0.004)\end{array}$ & -0.13 & $\begin{array}{c}0.002 \pm 0.05 \\
(0.02)\end{array}$ \\
\hline $\begin{array}{l}\text { MSC [11+] } \\
\text { vs. [1-5] }\end{array}$ & 0.006 & $\begin{array}{c}-0.005 \pm 0.07 \\
(0.84)\end{array}$ & -0.003 & $\begin{array}{c}-0.002 \pm 0.06 \\
(0.97)\end{array}$ \\
\hline Rank $\times$ Sex & 1.36 & $\begin{array}{c}-0.007 \pm 0.36 \\
(<0.001)\end{array}$ & 1.34 & $\begin{array}{c}0.009 \pm 0.37 \\
(0.002)\end{array}$ \\
\hline Sex $\times D C$ & 5.04 & $\begin{array}{c}0.03 \pm 1.45 \\
(0.004)\end{array}$ & 5.08 & $\begin{array}{c}0.09 \pm 1.47 \\
(<0.001)\end{array}$ \\
\hline Rank $\times$ DC & -1.03 & $\begin{array}{c}0.16 \pm 1.47 \\
(0.39)\end{array}$ & -1.23 & $\begin{array}{c}-0.20 \pm 1.52 \\
(0.33)\end{array}$ \\
\hline $\begin{array}{l}\text { MSC [6-10] } \\
\times \text { Sex }\end{array}$ & 0.21 & $\begin{array}{c}-0.001 \pm 0.12 \\
(0.07)\end{array}$ & --- & --- \\
\hline $\begin{array}{l}\text { MSC [11+] } \\
\times \text { Sex] }\end{array}$ & -0.05 & $\begin{array}{c}0.005 \pm 0.10 \\
(0.64)\end{array}$ & --- & --- \\
\hline $\begin{array}{l}\text { Rank } \times \text { DC } \\
\times \text { Sex }\end{array}$ & -4.89 & $\begin{array}{c}-0.07 \pm 2.30 \\
(0.04)\end{array}$ & -4.84 & $\begin{array}{c}-0.13 \pm 2.34 \\
(0.05)\end{array}$ \\
\hline
\end{tabular}

4 a DC = dominance certainty, ranging from 0 (certain) to 0.5 (ambiguous)

5 b $\mathrm{MSC}=$ matriline size category (small $=1-5 ;$ medium $=6-10$; large $=11+$ members $)$ 


\section{Table 4(on next page)}

Parameter coefficients from the top two models of aggression layer rank compared against the distribution of model coefficients (Mean \pm SD) generated from 1000 network randomizations. Coefficients with $p \leq 0.10$ (based upon randomizations; shown in parenth

${ }^{\mathrm{a}} \mathrm{DC}=$ dominance certainty, ranging from 0 (certain) to 0.5 (ambiguous) 
1 Table 4. Parameter coefficients from the top two models of aggression layer rank compared against the 2 distribution of model coefficients (Mean \pm SD) generated from 1000 network randomizations. Coefficients 3 with $p \leq 0.10$ (based upon randomizations; shown in parentheses) are in bold and italics.

\begin{tabular}{|c|c|c|c|c|}
\hline & Model 1 & Model 1 & Model 2 & Model 2 \\
\hline & $\begin{array}{l}\text { GLMM } \\
\text { Coeff's }\end{array}$ & $\begin{array}{c}\text { Randomization } \\
\text { Coefficients } \\
\text { Mean } \pm S D \\
\text { (p-value) }\end{array}$ & $\begin{array}{l}\text { GLMM } \\
\text { Coeff's }\end{array}$ & $\begin{array}{c}\text { Randomization } \\
\text { Coefficients } \\
\text { Mean } \pm \text { SD } \\
\text { (p-value })\end{array}$ \\
\hline Intercept & -1.47 & $\begin{array}{c}1.15 \pm 0.44 \\
(<0.001)\end{array}$ & -4.04 & $\begin{array}{c}1.15 \pm 0.94 \\
(<0.001)\end{array}$ \\
\hline Sex [male] & -2.29 & $\begin{array}{c}-0.007 \pm 0.63 \\
(<0.001)\end{array}$ & 0.09 & $\begin{array}{c}-0.0001 \pm 0.07 \\
(0.22)\end{array}$ \\
\hline Rank & 3.81 & $\begin{array}{c}-0.012 \pm 0.55 \\
(<0.001)\end{array}$ & 6.72 & $\begin{array}{c}-0.02 \pm 1.16 \\
(<0.001)\end{array}$ \\
\hline Age & --- & --- & 0.26 & $\begin{array}{c}-0.001 \pm 0.22 \\
(0.25)\end{array}$ \\
\hline $\mathrm{DC}^{\mathrm{a}}$ & 5.39 & $\begin{array}{c}-0.04 \pm 2.08 \\
(0.01)\end{array}$ & 16.67 & $\begin{array}{c}-0.0002 \pm 4.20 \\
(<0.001)\end{array}$ \\
\hline Rank $\times$ DC & -8.04 & $\begin{array}{c}0.12 \pm 2.75 \\
(0.005)\end{array}$ & -19.39 & $\begin{array}{c}0.07 \pm 5.55 \\
(0.002)\end{array}$ \\
\hline Sex $\times D C$ & 8.87 & $\begin{array}{c}0.05 \pm 3.02 \\
(0.004)\end{array}$ & --- & --- \\
\hline Rank $\times$ Sex & 2.49 & $\begin{array}{c}-0.01 \pm 0.79 \\
(0.002)\end{array}$ & --- & --- \\
\hline Age $\times$ DC & --- & --- & -1.21 & $\begin{array}{c}-0.002 \pm 0.93 \\
(0.20)\end{array}$ \\
\hline Rank $\times$ Age & -- & --- & -0.29 & $\begin{array}{c}0.001 \pm 0.24 \\
(0.24)\end{array}$ \\
\hline $\begin{array}{l}\text { Rank } \times \text { DC } \\
\times \text { Sex }\end{array}$ & -8.11 & $\begin{array}{c}-0.01 \pm 4.17 \\
(0.04)\end{array}$ & & \\
\hline $\begin{array}{l}\text { Rank } \times \text { DC } \\
\times \text { Age }\end{array}$ & & & 1.19 & $\begin{array}{c}0.0008 \pm 1.03 \\
(0.25)\end{array}$ \\
\hline
\end{tabular}

a $\mathrm{DC}=$ dominance certainty, ranging from 0 (certain) to 0.5 (ambiguous) 


\section{Table 5 (on next page)}

Parameter coefficients from the top model of status signaling layer rank compared against the distribution of model coefficients (Mean \pm SD) generated from 1000 network randomizations. Coefficients with $p \leq 0.10$ based upon randomizations (shown in parenth

${ }^{\mathrm{a}} \mathrm{DC}=$ dominance certainty, ranging from 0 (certain) to 0.5 (ambiguous) 
1 Table 5. Parameter coefficients from the top model of status signaling layer rank compared against the 2 distribution of model coefficients (Mean \pm SD) generated from 1000 network randomizations. Coefficients 3 with $p \leq 0.10$ based upon randomizations (shown in parentheses) are in bold and italics.

\begin{tabular}{|l|c|c|}
\hline & Model 1 & Model 1 \\
\hline & GLMM Coeff's & $\begin{array}{c}\text { Randomization } \\
\text { Coefficients } \\
\text { Mean } \pm \text { SD (p-value) }\end{array}$ \\
\hline Intercept & -0.86 & $\mathbf{0 . 6 9 \pm 0 . 3 2 ( < 0 . 0 0 1 )}$ \\
\hline Sex [male] & $\mathbf{- 2 . 6 7}$ & $\mathbf{0 . 0 5 \pm 0 . 5 0 ( < 0 . 0 0 1 )}$ \\
\hline Rank & $\mathbf{3 . 4 8}$ & $\begin{array}{c}-\mathbf{0 . 0 0 1} \pm 0.42 \\
(<0.001)\end{array}$ \\
\hline Age & 0.03 & $0.002 \pm 0.03(0.31)$ \\
\hline DCa & $-\mathbf{2 . 9 3}$ & $\mathbf{0 . 0 5 \pm 1 . 0 4 ( 0 . 0 0 4 )}$ \\
\hline Rank $\times$ Sex & $\mathbf{2 . 5 6}$ & $\begin{array}{c}-\mathbf{0 . 0 7} \pm 0.76 \\
(<0.001)\end{array}$ \\
\hline Rank $\times$ Age & -0.07 & $-0.002 \pm 0.05(0.17)$ \\
\hline Sex $\times$ Age & $\mathbf{0 . 3 8}$ & $\begin{array}{c}-\mathbf{0 . 0 2} \pm 0.11 \\
(<0.001)\end{array}$ \\
\hline $\begin{array}{l}\text { Rank } \times \text { Sex } \\
\times \text { Age }\end{array}$ & $-\mathbf{0 . 3 6}$ & $\mathbf{0 . 0 2 \pm 0 . 1 3 ( 0 . 0 0 4 )}$ \\
\hline
\end{tabular}

$4 \quad$ a DC = dominance certainty, ranging from 0 (certain) to 0.5 (ambiguous)

5 


\section{Table 6(on next page)}

Parameter coefficients from the top five models of grooming layer centrality rank compared against the distribution of model coefficients (Mean \pm SD) generated from 1000 network randomizations. Coefficients with $p \leq 0.10$ based upon randomizations (in pare

${ }^{\mathrm{a}} \mathrm{MSC}=$ matriline size category 
Table 6. Parameter coefficients from the top five models of grooming layer centrality rank compared against the distribution of model coefficients (Mean \pm SD) generated from 1000 network randomizations. Coefficients with $p \leq 0.10$ based upon randomizations (in parentheses) are in bold and 3 italics.

\begin{tabular}{|c|c|c|c|c|c|c|c|c|c|c|}
\hline & $\begin{array}{c}\text { Model } \\
1\end{array}$ & Model 1 & $\begin{array}{c}\text { Model } \\
2\end{array}$ & Model 2 & $\begin{array}{c}\text { Model } \\
3\end{array}$ & Model 3 & $\begin{array}{c}\text { Model } \\
4\end{array}$ & Model 4 & $\begin{array}{c}\text { Model } \\
5\end{array}$ & Model 5 \\
\hline & $\begin{array}{l}\text { GLMM } \\
\text { Coeff's }\end{array}$ & $\begin{array}{c}\text { Randomization } \\
\text { Coefficients } \\
\text { Mean } \pm \text { SD } \\
\text { (p-value) }\end{array}$ & $\begin{array}{l}\text { GLMM } \\
\text { Coeff's }\end{array}$ & $\begin{array}{c}\text { Randomization } \\
\text { Coefficients } \\
\text { Mean } \pm \text { SD } \\
\text { (p-value) }\end{array}$ & $\begin{array}{l}\text { GLMM } \\
\text { Coeff's }\end{array}$ & $\begin{array}{c}\text { Randomization } \\
\text { Coefficients } \\
\text { Mean } \pm \text { SD } \\
\text { (p-value) }\end{array}$ & $\begin{array}{l}\text { GLMM } \\
\text { Coeff's }\end{array}$ & $\begin{array}{c}\text { Randomization } \\
\text { Coefficients } \\
\text { Mean } \pm \text { SD } \\
\text { (p-value) }\end{array}$ & $\begin{array}{l}\text { GLMM } \\
\text { Coeff's }\end{array}$ & $\begin{array}{c}\text { Randomization } \\
\text { Coefficients } \\
\text { Mean } \pm \text { SD } \\
\text { (p-value) }\end{array}$ \\
\hline Intercept & 0.74 & $\begin{array}{c}1.11 \pm 0.12 \\
(0.002)\end{array}$ & 0.72 & $\begin{array}{c}1.12 \pm 0.12 \\
(0.002)\end{array}$ & 0.94 & $\begin{array}{c}1.13 \pm 0.09 \\
(0.03)\end{array}$ & 0.97 & $\begin{array}{c}1.13 \pm 0.09 \\
(0.09)\end{array}$ & 0.92 & $\begin{array}{c}1.12 \pm 0.09 \\
(0.02)\end{array}$ \\
\hline Rank & 1.14 & $\begin{array}{c}0.04 \pm 0.25 \\
(<0.001)\end{array}$ & 1.11 & $\begin{array}{c}0.008 \pm 0.25 \\
(<0.001)\end{array}$ & 0.65 & $\begin{array}{c}-0.01 \pm 0.11 \\
(<0.001)\end{array}$ & 0.51 & $\begin{array}{c}-0.02 \pm 0.14 \\
(<0.001)\end{array}$ & 0.64 & $\begin{array}{c}-0.009 \pm 0.11 \\
(<0.001)\end{array}$ \\
\hline $\begin{array}{l}\text { Sex } \\
\text { [male] }\end{array}$ & -0.35 & $\begin{array}{c}-0.005 \pm 0.07 \\
(<0.001)\end{array}$ & -0.34 & $\begin{array}{c}-0.004 \pm 0.07 \\
(<0.001)\end{array}$ & -0.32 & $\begin{array}{c}-0.002 \pm 0.07 \\
(0.001)\end{array}$ & -0.47 & $\begin{array}{c}-0.02 \pm 0.12 \\
(<0.001)\end{array}$ & -0.30 & $\begin{array}{c}0.001 \pm 0.07 \\
(<0.001)\end{array}$ \\
\hline $\begin{array}{l}\text { aMSC } \\
{[6-10]} \\
\text { vs. [1-5] }\end{array}$ & -0.12 & $\begin{array}{c}-0.04 \pm 0.19 \\
(0.41)\end{array}$ & -0.12 & $\begin{array}{c}0.03 \pm 0.18 \\
(0.45)\end{array}$ & -0.25 & $\begin{array}{c}-0.03 \pm 0.10 \\
(0.008)\end{array}$ & -0.23 & $\begin{array}{c}-0.03 \pm 0.10 \\
(0.008)\end{array}$ & -0.24 & $\begin{array}{c}0.03 \pm 0.10 \\
(0.01)\end{array}$ \\
\hline $\begin{array}{l}\text { aMSC } \\
{[11+] \text { vs. }} \\
{[1-5]}\end{array}$ & 0.38 & $\begin{array}{c}0.08 \pm 0.14 \\
(0.03)\end{array}$ & 0.39 & $\begin{array}{c}0.06 \pm 0.14 \\
(0.03)\end{array}$ & 0.03 & $\begin{array}{c}0.05 \pm 0.08 \\
(0.85)\end{array}$ & 0.08 & $\begin{array}{c}0.05 \pm 0.08 \\
(0.64)\end{array}$ & 0.06 & $\begin{array}{c}0.05 \pm 0.08 \\
(0.89)\end{array}$ \\
\hline $\begin{array}{l}\text { Rearing } \\
\text { [nursery] }\end{array}$ & -0.21 & $\begin{array}{c}-0.03 \pm 0.13 \\
(0.19)\end{array}$ & --- & --- & -0.19 & $\begin{array}{c}-0.03 \pm 0.013 \\
(0.22)\end{array}$ & --- & --- & --- & --- \\
\hline $\begin{array}{l}\text { Rank } \times \\
\text { MSC [6- } \\
10]\end{array}$ & -0.33 & $\begin{array}{c}-0.04 \pm 0.37 \\
(0.47)\end{array}$ & -0.30 & $\begin{array}{c}-0.005 \pm 0.35 \\
(0.39)\end{array}$ & --- & --- & --- & --- & --- & --- \\
\hline $\begin{array}{l}\text { Rank } \times \\
\text { MSC } \\
{[11+]}\end{array}$ & -0.72 & $\begin{array}{c}-0.07 \pm 0.30 \\
(0.02)\end{array}$ & -0.69 & $\begin{array}{c}-0.03 \pm 0.29 \\
(0.03)\end{array}$ & --- & --- & --- & --- & --- & --- \\
\hline $\begin{array}{l}\text { Rank } \times \\
\text { Sex } \\
\text { [male] }\end{array}$ & --- & --- & --- & --- & --- & --- & 0.34 & $\begin{array}{c}0.04 \pm 0.23 \\
(0.19)\end{array}$ & --- & --- \\
\hline
\end{tabular}




\section{Table 7 (on next page)}

Which animals occupy top consensus ranks for each study group

${ }^{a} A M$ - adult male ${ }^{b} A F$ - adult female ${ }^{c} S A M$ - subadult male ${ }^{d} \alpha-A M$ - alpha male ${ }^{\text {e}} \beta-A M$ - beta male ${ }^{f} \alpha-A F-$ alpha female ${ }^{9} \beta-A F-$ beta female 
1 Table 7. Which animals occupy top consensus ranks for each study group

\section{Consensus}

Rank

Position

1

2

3

4

5

6
A

$\mathrm{AM}^{\mathrm{a}}$

$\mathrm{AF}^{\mathrm{b}}$

$\mathrm{AM}$

$\mathrm{AF}$

AM

$\mathrm{SAM}^{\mathrm{c}}$

2 aAM - adult male

3 bAF - adult female

4 'SAM - subadult male

$5{ }^{\mathrm{d}} \alpha$-AM - alpha male

6 e $\beta$-AM - beta male

$7 \quad{ }^{\mathrm{f}} \alpha-\mathrm{AF}$ - alpha female

8 g $\beta$-AF - beta female

9

10

B $\quad$ C $\quad$ D

$\mathrm{AF}$

$\beta-\mathrm{AM}^{\mathrm{e}}$

$\mathrm{AF}$

AF

AF

AF
$\mathrm{AF}$

AF

$\beta-A M$

$\beta-\mathrm{AF}$

AF

AF
D

$\alpha-A M^{d}$

$\mathrm{AF}$

$\alpha-\mathrm{AF}^{\mathrm{f}}$

$\mathrm{AF}$

AF

AF
$\mathbf{E}$

$\beta$-AM

$\alpha-\mathrm{AM}$

$\beta-\mathrm{AF}^{\mathrm{g}}$

$\mathrm{AM}$

AF

$\alpha-A F$
F

AM

AM

AM

AM

$\alpha$-AM

AF
G

$\beta$-AM

$\alpha-\mathrm{AF}$

AF

AF

$\mathrm{AF}$

$\alpha$-AM (1) 